\title{
Antibacterial Properties of Canine Platelet-Rich Plasma and Other Non-Transfusional Hemo-Components: An in vitro Study
}

OPEN ACCESS

Edited by:

Roberta Perego,

University of Milan, Italy

Reviewed by:

Piera Anna Martino, University of Milan, Italy

Livia Camargo Garbin,

The University of the West Indies St.

Augustine, Trinidad and Tobago

*Correspondence:

Adolfo Maria Tambella

adolfomaria.tambella@unicam.it

tThese authors have contributed equally to this work

Specialty section:

This article was submitted to Comparative and Clinical Medicine,

a section of the journal

Frontiers in Veterinary Science

Received: 24 July 2021 Accepted: 26 August 2021 Published: 04 October 2021

Citation:

Attili A-R, lacoucci $C$, Serri $E$, Cuteri V Cantalamessa A, Linardi M, Rifici $C$, Mazzullo G, Rossi G, Galosi L and

Tambella AM (2021) Antibacterial

Properties of Canine Platelet-Rich Plasma and Other Non-Transfusional Hemo-Components: An in vitro Study.

Front. Vet. Sci. 8:746809. doi: 10.3389/fvets.2021.746809

\begin{abstract}
Anna-Rita Attili ${ }^{1 \dagger}$, Cristina lacoucci ${ }^{1 \dagger}$, Evelina Serri ${ }^{2}$, Vincenzo Cuteri ${ }^{1}$, Andrea Cantalamessa ${ }^{1}$, Martina Linardi ${ }^{1}$, Claudia Rifici ${ }^{3}$, Giuseppe Mazzullo ${ }^{3}$, Giacomo Rossi ${ }^{4}$, Livio Galosi ${ }^{4}$ and Adolfo Maria Tambella ${ }^{2 *}$
\end{abstract}

'Laboratory of Medical Microbiology and Infectious Diseases, School of Biosciences and Veterinary Medicine, University of Camerino, Matelica, Italy, ${ }^{2}$ Veterinary Teaching Hospital, School of Biosciences and Veterinary Medicine, University of Camerino, Matelica, Italy, ${ }^{3}$ Pathology Laboratory, Department of Veterinary Sciences, University of Messina, Messina, Italy, ${ }^{4}$ Pathology Laboratory, School of Biosciences and Veterinary Medicine, University of Camerino, Matelica, Italy

This in vitro study was carried out to evaluate the potential antibacterial properties of canine non-transfusional hemo-components. Therapeutic formulations commonly used for regenerative medicine purposes (platelet-rich plasma, platelet gel, platelet lysate, fibrin glue), considering both leukocyte-rich and leukocyte-poor formulations, but also platelet-poor plasma and activating substances (thrombin, calcium gluconate), were tested to detect elements with potential antimicrobial properties. The antibacterial effect was tested on different bacterial strains (Staphylococcus aureus subspecies aureus, Staphylococcus cohnii subspecies cohnii, Escherichia coli, Pseudomonas aeruginosa, and Klebsiella pneumoniae subspecies pneumoniae) isolated from canine wounds and classified as susceptible, multidrug-, extensively, and pandrug-resistant bacteria toward a known panel of human and veterinary antibiotics. The evaluation was carried out by agar gel diffusion method (Kirby-Bauer) and micro-inhibition in broth using microplates and spectrophotometer reading. The study findings confirmed the hypothesized antibacterial properties of canine non-transfusional hemo-components. A more effective bacteriostatic effect was found against Gram-negative bacteria, drug-resistant too. The presence of leukocytes or platelets does not appear to be essential for the antibacterial effect. Further studies should be conducted to evaluate the exact mechanism of action of the antimicrobial activity. However, non-transfusional hemo-components could be a useful natural aid in controlling bacterial infections in dogs.

Keywords: platelet-rich plasma, platelet-poor plasma, platelet lysate, platelet concentrates, leucocytes, antibacterial effect, dogs

\section{INTRODUCTION}

Antimicrobial resistance (AMR) is a multifaceted topic at the interface of human, animal, and plant health, food hygiene, and environmental sciences, resulting to be a major global public health issue of the 21 st century $(1,2)$.

To counter this increasing phenomenon, both in human and in veterinary medicine, more and more scientists are looking for molecules that can assist or replace the action of antibiotics. 
The topical use of non-transfusional hemo-components or autologous platelet concentrates (PCs), including platelet-rich plasma (PRP), platelet gel (PG), platelet lysate (PL), and fibrin glue (FG), has gained great popularity during the past 20 years; thus, they have been used, mainly for their regenerative properties, in a variety of human medical fields such as orthopedics (3-7), wound healing (8-12), ophthalmology (13$15)$, and dentistry (16-20). Despite a recent growing interest, fewer in vivo and in vitro studies in dogs have been published (21-26).

While the potential regenerative effect of PCs has been extensively studied, fewer studies have investigated the possible relationship with bacterial growth. Some authors have empirically supposed that PCs could promote infections, associating them with microbiological culture media and acting as a substrate for the growth of bacteria (27). More recently, on the contrary to this theory, some evidence would attribute to PCs an inhibitory effect on bacterial growth, although the results cannot be considered definitive yet (27-31). The antibacterial properties of PCs are supported by some in vitro studies conducted mostly in humans $(28,30,32-50)$, but also in horses $(31,51,52)$ and rabbits (53). Systematic reviews of current literature considering in vitro, preclinical, and clinical studies have shown that PCs may have antibacterial properties (54-56).

The antibacterial effect of PCs has also been recently highlighted in in vivo studies on surgical wounds (57), sternotomy wounds $(58,59)$, osteomyelitis (60-62), spinal infections (63), and bacterial cystitis (64), while another in vivo study showed controversial results (65). Since infection control is a prerequisite for the wound healing process and for avoiding the chronicization event, recently, in a small controlled clinical trial performed in dogs, MRSA-infected skin wounds treated with PRP showed an accelerated healing process with rapid reepithelialization and granulation tissue formation, reduction of inflammation, and decrease of bacterial loads (66).

Until now, the components of the PCs that control antimicrobial activity have not been fully understood, so the mechanisms of PC interaction with bacteria need further investigation.

In order to detect any elements potentially endowed with antimicrobial properties, we explored the antimicrobial activity of PCs (PRP, PG, PL, FG) against susceptible (S), multidrug-resistant (MDR) extensively drug-resistant (XDR), and pandrug-resistant (PDR) Gram-positive and Gram-negative microorganisms isolated from canine wounds. In this set of in vitro investigations, leukocyte-rich (L-PRP, L-PG) and leukocytepoor formulations (P-PRP, P-PG), but also platelet-poor plasma (L-PPP, P-PPP) and intermediate elements of the PC production process (thrombin, calcium gluconate), were evaluated.

\section{MATERIALS AND METHODS}

\section{Animals and Blood Collection}

The study was performed complying with the Animal Welfare Body of the University of Camerino (protocol number E81AC.10/A) according to the National Legislative Decree n. 26/2014, implementation of EU Directive 2010/63/EU. Blood was collected from five owned dogs at the Veterinary Teaching Hospital, School of Biosciences and Veterinary Medicine, University of Camerino. The owner's informed consent was obtained for participation in the study. All animals were between 1 and 10 years of age, had a minimum body weight of $15 \mathrm{~kg}$, and belonged to different dog breeds (three mixed breed, one Labrador retriever, one English setter). They had no noteworthy medical problems or medical history, except for degenerative joint disease, and did not take any medications. An articular infiltration of autologous PRP was practiced in each dog for the management of degenerative joint disease; an aliquot of whole blood in excess of the amount needed for PRP preparation was used for the in vitro investigations of the present study. Each dog, upon admission, had a complete physical examination, complete blood count, and serum biochemical profile. No animals had platelet disorders or took anticoagulant and antibiotic drugs.

\section{Preparation of Hemo-Components}

In each dog, fresh autologous whole blood $(50 \mathrm{ml})$ was collected from the jugular vein using a $60-\mathrm{ml}$ syringe containing anticoagulant citrate dextrose solution A (ACD-A: SALF SpA, Cenate Sotto, Bergamo, Italy) in a ratio of 1:9. Blood collection and preparation procedures were performed as described by Tambella and collaborators (22) in aseptic conditions through a laminar flow cabin (Bicasa, Bernareggio, MB, Italy) and following the Good Laboratory Practices. The hemo-components were obtained from a pool of fresh canine whole blood. Prior to preparation of each hemo-component, an aliquot was used to determine the blood cell count.

\section{Autologous Thrombin}

The thrombin-rich solution was obtained from autologous whole blood which was centrifuged (Rotina 46R, Hettich, Milan, Italy) at $650 \mathrm{~g}$ for $10 \mathrm{~min}$. The plasma supernatant fraction was mixed with $10 \%$ calcium gluconate (B. Braun, Melsungen, Germany) in a ratio of 5:1 and incubated (cooled incubator IL 23R, VWR Incu-Line, Milan, Italy) at $37^{\circ} \mathrm{C}$ for $30 \mathrm{~min}$. The resulting clot was crushed, and the final supernatant, the thrombin-rich solution, was collected for PRP activation.

\section{Leukocyte-Rich -PPP, -PRP, and -PG}

As described by Tambella et al. (22), leukocyte-rich plateletpoor plasma (L-PPP), leukocyte PRP (L-PRP), and leukocyte PG (L-PG) were obtained by a double-spin technique. Whole blood was centrifuged (Rotina 46R, Hettich, Milan, Italy) at $180 \mathrm{~g}$ for $20 \mathrm{~min}$. To stratify the concentrated platelet pellet in the bottom layer, and platelet poor plasma (L-PPP) in the supernatant layer, the plasma with the buffy coat layer was centrifuged at $650 \mathrm{~g}$ for $15 \mathrm{~min}$. A half amount of L-PPP was picked up and used for the in vitro study. By resuspending the PCs in the residual part of PPP, the L-PRP was obtained. A half amount of L-PRP was used for the in vitro study; to obtain L-PG, the residual L-PRP was transferred in sterile glass Petri dishes and mixed with the thrombin-rich solution and the calcium gluconate in a volumetric ratio of 8:1:0.5. The L-PG production was achieved at room temperature in $5 \mathrm{~min}$. 


\section{Leukocyte-Poor (Pure) -PPP, -PRP, and -PG}

Pure platelet-poor plasma (P-PPP), pure platelet-rich plasma (P-PRP), and pure platelet gel (P-PG) were obtained by a doublespin technique. In order to reduce the leukocyte concentration as much as possible, the first centrifugation of whole blood was performed at $500 \mathrm{~g}$ for $20 \mathrm{~min}$ using tubes (VF108SAS Venosafe, Terumo Europe NV, Leuven, Belgium) containing a gel enabling the separation of the different blood components. The plasma fraction was then centrifuged at 2,000 $\mathrm{g}$ for $10 \mathrm{~min}$ to achieve separation of P-PPP (the supernatant half-fraction) from P-PRP (the residual half-fraction). Similarly, P-PG was obtained by mixing P-PRP with the autologous thrombin-rich solution and calcium gluconate.

\section{FG}

Fibrinogen concentrate, the precursor of FG, was obtained following the method proposed by Tarantino et al. (67). This method is characterized by physical separation (centrifugation) and the presence of a special membrane, capable of concentrating fibrinogen. After centrifugation of whole blood $(2,000 \mathrm{~g}$ for $10 \mathrm{~min}$ ), the plasma fraction obtained without buffy coat was transferred in special tubes (Amicon Ultra 15, Merck Millipore Ltd, Tullagreen, Carrigtwohill, Co Cork, Ireland) with a 100,000 MWCO (molecular weight cutoff) porosity filter. Then, tubes were centrifuged at $3,600 \mathrm{~g}$ for $45 \mathrm{~min}$ and the fibrinogen concentrate above the filter was obtained.

\section{PL}

PL was produced as reported in previous studies with some modifications $(68,69)$. Using a two-step centrifugation protocol (180 $g$ for 20 minutes and 1,500 $g$ for 10 minutes), packed PC was produced from whole blood with ACD-A. To remove platelet membranes and other cellular debris and obtain the PL, three repeated cycles of freezing (at $-20^{\circ} \mathrm{C}$ ) and thawing (at room temperature) followed by centrifugation at 2,500 $\mathrm{g}$ for $20 \mathrm{~min}$ were undergone obtaining the PL as supernatant.

\section{Evaluation of Antibacterial Activity Bacterial Strains and Their Antibiotic Susceptibility Evaluation}

To compare the antibacterial effect of each hemo-component, strains isolated from canine wounds were selected from the bacterial collection of the Laboratory of Microbiology and Infectious Diseases, School of Bioscience and Veterinary Medicine, University of Camerino, based on their ability to cause also infections in the surgical setting.

Three different frozen strains of Staphylococcus aureus subspecies aureus, one Staphylococcus cohnii subspecies cohnii, three Klebsiella pneumoniae subspecies pneumoniae, two Pseudomonas aeruginosa, and three Escherichia coli strains were thawed and reconstituted. In addition, Staphylococcus aureus subspecies aureus ATCC $\mathbb{R} 43300^{\mathrm{TM}}$ strain was used as control. After pre-enrichment in Tryptic Soy Broth (TSB) (Liofilchem, Roseto degli Abruzzi, Italy) and incubation at $37^{\circ} \mathrm{C}$ for $6 \mathrm{~h}$ in aerobic condition, a loop was shown on Columbia Blood Agar (Liofilchem, Italy), Mannitol Salt Agar (Liofilchem, Italy), MacConkey Agar (Liofilchem, Italy), and Pseudomonas
Cetrimide Agar (Liofilchem, Italy) and incubated aerobically at $37^{\circ} \mathrm{C}$ for $24 \mathrm{~h}$. Colonies were identified and confirmed by MALDI-TOF MS (Bruker Daltonics, Hamburg, Germany).

In order to determine their antibiotic susceptibility profile and classify the strains as susceptible, MDR, XDR, and PDR (70), antimicrobial susceptibility testing toward 16 commercial human and veterinary antibiotics, belonging to eight different classes, was performed according to the Clinical and Laboratory Standards Institute and EUCAST guidelines (71, 72). The standard disk diffusion method (Kirby-Bauer test) was used to test amoxicillin and clavulanic acid (AUG $30 \mu \mathrm{g}$ ), penicillin (P 1 UI), oxacillin (OX $1 \mu \mathrm{g}$ ), cefadroxil (CDX $30 \mu \mathrm{g}$ ), cefoxitin (CFX $30 \mu \mathrm{g}$ ), cefquinome (CEQ $30 \mu \mathrm{g}$ ), enrofloxacin (ENR $5 \mu \mathrm{g}$ ), gentamicin (CN $10 \mu \mathrm{g}$ ), sulfamethoxazole and trimethoprim (SXT $25 \mu \mathrm{g}$ ), tetracycline (TE $30 \mu \mathrm{g}$ ), amikacin (AK $30 \mu \mathrm{g}$ ), streptomycin (S $300 \mu \mathrm{g}$ ), metronidazole (M 50 $\mu \mathrm{g}$ ), and polymyxin B (PB $300 \mu \mathrm{g})$. The E-test method was used for Staphylococcus strains to determine the MICs against vancomycin (VA), and teicoplanin (TEC), as described by the manufacturer (MIC Test Strip, Liofilchem, Italy).

\section{Antibacterial in vitro Evaluation of Hemo-Components}

To evaluate the antibacterial effect of different hemo-components and activating agents (PL, FG, thrombin, L-PPP, P-PPP, L-PRP with calcium gluconate, P-PRP with calcium gluconate, L-PRP with thrombin, P-PRP with thrombin, L-PG $35 \mu$, P-PG 35 $\mu \mathrm{l}$, L-PG $500 \mu \mathrm{l}$, and P-PG $500 \mu \mathrm{l}$ ), the Kirby-Bauer disk diffusion method and the broth inhibition by microtiter method were performed.

\section{Kirby-Bauer Disk Diffusion Method}

Following the CLSI (2018) recommendations (71), each microorganism was suspended in sterile saline solution (Thermo Fisher, Milan, Italy) to obtain an optical density equal to $0.5 \mathrm{McF}$ arland $\left(1 \times 10^{8} \mathrm{CFU} / \mathrm{ml}\right)$, verified at $550 \mathrm{~nm}$ by a spectrophotometer (Jenway, Genova Nano, Bibby Scientific, Staffordshire, UK). A sterile cotton swab was dipped into the inoculum suspension and the excess fluid removed by turning the swab against the inside of the tube to avoid over-inoculation of plates. The inoculum was spread evenly over the entire surface of the Mueller Hinton II agar plate ( $\mathrm{MH}$; Liofilchem, Italy) by swabbing in three directions. Each hemo-component was placed by a micropipette (PIPETMAN L P20L 2-20 $\mu$ l, Gilson, Milan, Italy) on the surface of the media, in contact with the microorganisms to reduce as much as possible the variables that could influence their actions against bacteria. Specifically, four different Petri dishes were used to test hemo-components with and without leukocytes against each microorganism.

The amount of each liquid hemo-component was $8 \mu l$, except for PG, tested at 35 and $500 \mu \mathrm{k}$, in the prejellification phase. Positive controls were performed inoculating the microbial suspension (McFarland 0.5) on MH (Liofilchem, Italy) alone, whereas the same media inoculated with saline solution or hemo-components, with and without leukocytes only, represented the negative controls. The assay was conducted in duplicate and repeated twice. All plates were incubated 
at $37^{\circ} \mathrm{C}$ aerobically and evaluated after 4, 8, and $24 \mathrm{~h}$. For each strain, areas $(\mathrm{mm})$ with bacterial inhibition or areas with few bacterial colonies were compared to the respective positive control.

\section{Broth Inhibition by Microtiter Method}

The antibacterial activity was determined using the broth inhibition by microtiter method. Bacterial strains have been grown in Tryptic Soy Broth (Liofilchem, Italy) at $37^{\circ} \mathrm{C}$ for $6 \mathrm{~h}$, aerobically. The final inoculum concentration was adjusted using a spectrophotometer (Jenway, Genova Nano, Bibby Scientific, Staffordshire, UK) to $1 \times 10^{4} \mathrm{CFU} / \mathrm{ml}\left(\mathrm{OD}_{540 \mathrm{~nm}}\right)$, and $20 \mu \mathrm{l}$ of each bacterial suspension was inoculated into a 96 -well microtiter plate (Sero-Wel ${ }^{\circledR}$, Bibby Sterilin Ltd., UK) containing $10 \mu \mathrm{l}$ of each hemo-component (PL, FG, L-PRP, P-PRP, L-PRP plus thrombin, P-PRP plus thrombin, L-PRP plus calcium gluconate, P-PRP plus calcium gluconate, L-PPP, P-PPP) and $170 \mu \mathrm{l}$ of sterile TSB. Quantities of 10, 20, 40, and $180 \mu$ l were used for pre-jellification L-PG and P-PG to test the antimicrobial activity toward $20 \mu \mathrm{l}$ of each bacterial suspension. Each well was tested with the respective negative control represented by the same quantities of the hemo-components only. Positive controls with $20 \mu \mathrm{l}$ of each bacterial suspension in $170 \mu \mathrm{l}$ of sterile TSB were considered. As a blank negative control, an amount of $170 \mu \mathrm{l}$ of sterile TSB was placed in the first and last wells of each plate. In addition, wells containing only each hemo-component were used as negative controls. No $0.01 \%$ acetic acid was added to prevent peptide aggregation and release of platelet contents. The microtiter plates were incubated at $37^{\circ} \mathrm{C}$ aerobically under slow and continuous agitation (300 g/minute) (Asal 715, Milano, Italy) and evaluated after 4,18 , and $24 \mathrm{~h}$ of incubation. A visual assessment (48) was conducted after $4 \mathrm{~h}$, while at 18 and $24 \mathrm{~h}$ the observations were read using a spectrophotometer (Multiskan Ascent, Thermo Scientific, Waltham, MA, USA), at a wavelength of $540 \mathrm{~nm}$. The test was repeated twice.

\section{Statistical Analysis}

All experiments were performed in duplicate. Statistical differences between quantitative variables (mean $\mathrm{OD}_{540 \mathrm{~nm}}$ ) were evaluated with Student's $t$-test. To determine the antimicrobial activity, the mean optical density $\left(\mathrm{OD}_{540 \mathrm{~nm}}\right)$ value recorded for each microorganism and the hemo-component, less the $\mathrm{OD}_{540 \mathrm{~nm}}$ value recorded for each hemo-component, was compared to the respective positive controls recorded at the same time. Mean OD values for the different bacteria (susceptible or drug-resistant Gram-positive and Gram-negative strains) and recorded at different times (18-24h) were analyzed with and without the leukocyte component.

Finally, the mean OD values of bacterial concentrations in the presence of hemo-components with leukocytes were compared with the mean OD values observed in the presence of hemocomponents without leukocytes. STATA version 13.0 (STATA Corporation, College Station, TX, USA) was used to conduct the statistical analysis. A $p$ value less than 0.05 was considered statistically significant.

\section{RESULTS}

\section{Preparation of Hemo-Components and Whole Blood and Hemo-Component Cell Counts}

No technical problems occurred during the preparation of non-transfusional hemo-components. Each hemo-component was easily produced using common laboratory tools and was ready for use in this in vitro study. Cell concentrations were appropriate for the specific characteristics requested for each hemo-component.

In L-PRP and L-PG, platelet concentrations increased by 4.3fold and leukocyte concentrations increased 2.1-fold compared with whole blood (WB) baseline values.

In L-PPP, platelet count decreased approximately 142fold compared with L-PRP and leukocytes decreased approximately 45 -fold.

As expected, the pure formulations (P-PRP, P-PG, and P-PPP) were leukocyte-depleted. Platelet concentrations in P-PRP and P-PG increased 2.2-fold from WB.

Both platelet and leukocyte concentrations were very low in P-PPP and FG.

There were no detectable blood cells in PL.

The mean number of platelets and white blood cells obtained by blood count analysis from the WB pool and the different hemo-components are reported in Table $\mathbf{1 .}$

\section{Bacterial Strains and Their Antibiotic Susceptibility Evaluation}

Among the selected Gram-positive and Gram-negative microorganisms, different susceptibility profiles were observed and classified (Table 2) (70). One strain of S. aureus subspecies aureus and $S$. cohnii subspecies cohnii, one strain of $K$. pneumoniae subspecies pneumoniae, and one strain of $E$. coli resulted to be susceptible to the panel of antibiotics, and one strain of $S$. aureus subspecies aureus, $P$. aeruginosa, K. pneumoniae ssp. pneumoniae, and E. coli were MDR, while one strain of $S$. aureus subspecies aureus, $K$. pneumoniae ssp. pneumoniae, and E. coli resulted to be extensively drug-resistant. Only one strain of $P$. aeruginosa was PDR.

\section{Antibacterial Effect Evaluation of the Hemo-Components Kirby-Bauer Method}

After $4 \mathrm{~h}$ of incubation at $37^{\circ} \mathrm{C}$ under aerobic conditions, no inhibition zones were observed for Gram-positive bacteria. Among Gram-negative microorganisms, some inhibition zones were observed for susceptible K. pneumoniae strains cultured with P-PG and L-PG. In particular, increased mean inhibition zones of $2.5 \times 4.5 \mathrm{~mm}, 7.5 \times 10 \mathrm{~mm}$, and $8.5 \times 50 \mathrm{~mm}$ were recorded for P-PG $35 \mu \mathrm{l}$, P-PG $500 \mu \mathrm{l}$, and L-PG $500 \mu \mathrm{l}$, respectively (Figure 1).

The MDR K. pneumoniae ssp. pneumoniae strain showed a zone of inhibition to all hemo-components, except for calcium gluconate, and P-PRP plus calcium and thrombin (Table 3, Figures 2, 3). PG showed a greater antibacterial effect, 
TABLE 1 | Leukocyte and platelet concentrations obtained from whole blood (pool of $250 \mathrm{ml}$ from five dogs) and each hemo-component.

\begin{tabular}{|c|c|c|c|c|c|c|c|c|}
\hline \multicolumn{9}{|c|}{ Cell count evaluation } \\
\hline & WB & L-PRP/L-PG & L-PPP & P-PRP/P-PG & P-PPP & $\mathbf{F G}$ & PL & $\mathbf{T}$ \\
\hline WBC & 8.71 & 18.29 & 0.40 & 0.18 & 0.10 & 0.07 & nd & nd \\
\hline PLT & 265 & 1139 & 8 & 583 & 1 & 3 & nd & nd \\
\hline
\end{tabular}

$W B C=$ number of leukocytes $\times 10^{3} / \mu l ; P L T=$ number of platelets $\times 10^{3} / \mu l$; WB, whole blood (pool of $250 \mathrm{ml}$ ); L-PRP, leukocyte platelet-rich plasma; L-PG, leukocyte platelet gel; L-PPP, leukocyte platelet-poor plasma (L-PPP); P-PRP, pure platelet-rich plasma; P-PG, pure platelet gel; P-PPP, pure platelet-poor plasma; FG, fibrin glue; PL, platelet lysate; T, thrombin-rich solution; nd, not detectable.

TABLE 2 | Antimicrobial resistance profiles of microorganisms selected and identified by MALDI-TOF MS from canine wounds.

\begin{tabular}{|c|c|c|c|c|c|}
\hline Bacterial species & Resistance profiles & $\mathbf{S}$ & MDR & XDR & PDR \\
\hline S. aureus ssp. aureus & ENR-TE & $x$ & & & \\
\hline S. cohnii ssp. cohnii & AUG-P-OX & $x$ & & & \\
\hline K. pneumoniae ssp. pneumoniae & SXT-M & $x$ & & & \\
\hline E. coli & M & $x$ & & & \\
\hline S. aureus ssp. aureus & P-ENR-SXT & & $x$ & & \\
\hline K. pneumoniae ssp. pneumoniae & AUG-P-TE-M & & $x$ & & \\
\hline E. coli & SXT-TE-M & & $x$ & & \\
\hline$P$. aeruginosa & ENR-SXT-TE-M & & $x$ & & \\
\hline S. aureus ssp. aureus & AUG-OX-P-CDX-CFX- ENR-SXT-TE-S & & & $x$ & \\
\hline K. pneumoniae ssp. pneumoniae & AUG-P-CDX-CFX- ENR-SXT-TE-S-M & & & $x$ & \\
\hline E. coli & AUG-P-CDX-CFX-CEQ-ENR-SXT-TE-S-M & & & $x$ & \\
\hline$P$. aeruginosa & AUG-P-CDX-CFX-CEQ-ENR-CN-SXT-TE-AK-S-M-PB & & & & $x$ \\
\hline
\end{tabular}

MALDI-TOF MS, matrix-assisted laser desorption ionization-time-of-flight mass spectrometry; S, susceptible; MDR, multidrug-resistant; XDR, extensively drug-resistant; PDR, pandrug-

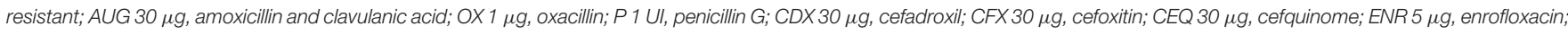
CN $10 \mu \mathrm{g}$, gentamicin; SXT $25 \mu \mathrm{g}$, sulfamethoxazole and trimethoprim; TE $30 \mu \mathrm{g}$, tetracycline; AK $30 \mu \mathrm{g}$, amikacin; S $300 \mu \mathrm{g}$, streptomycin; M 50 $\mu \mathrm{g}$, metronidazole; PB 300 gg, polymyxin B; MIC VA, vancomycin; MIC TEC, teicoplanin.

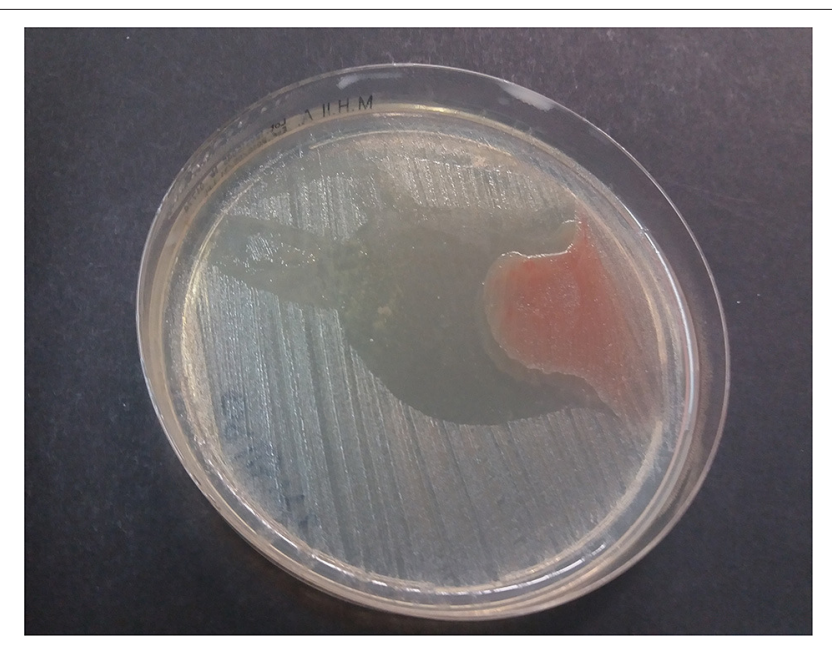

FIGURE 1 | L-PG $500 \mu$ l effect against susceptible K. pneumoniae ssp. pneumoniae strain after $4 \mathrm{~h}$ at $37^{\circ} \mathrm{C}$ aerobically.

although non-significant differences were recorded between hemo-components both with and without leukocytes.

For extensively drug-resistant $K$. pneumoniae ssp. pneumoniae strains, inhibition zones of $2 \times 3.5 \mathrm{~mm}, 4.5 \times 37.5 \mathrm{~mm}$, and $5 \times$
TABLE 3 | Inhibition zones recorded by each hemo-component for multidrug-resistant $K$. pneumoniae ssp. pneumoniae after $4 \mathrm{~h}$ of incubation using the Kirby-Bauer method.

\section{Hemo-components} Inhibition zone (mm)

Platelet lysate

$9 \times 10$

Fibrin glue

$9 \times 12$

L-PRP

$8.5 \times 9$

P-PRP

$9 \times 9$

L-PRP plus thrombin

$9.5 \times 9.5$

P-PRP plus thrombin

$9 \times 9$

L-PRP plus calcium gluconate

$9 \times 10$

L-PPP

P-PPP

$9.5 \times 10$

$9 \times 9$

L-PG $35 \mu \mathrm{l}$

$19 \times 20$

P-PG $35 \mu l$

$8 \times 18$

L-PG $500 \mu \mathrm{l}$

$38 \times 45$

P-PG $500 \mu \mathrm{l}$

$28 \times 64$

$\overline{L-P R P, ~ l e u k o c y t e ~ p l a t e l e t-r i c h ~ p l a s m a ; ~ P-P R P, ~ p u r e ~ p l a t e l e t-r i c h ~ p l a s m a ; ~ L-P P P, ~ l e u k o c y t e ~}$ platelet-poor plasma; P-PPP, pure platelet-poor plasma: L-PG, leukocyte platelet gel; P-PG: pure platelet gel.

$38 \mathrm{~mm}$ were observed for P-PG $35 \mu \mathrm{l}$, P-PG $500 \mu \mathrm{l}$, and L-PG 500 $\mu$ l, respectively. 


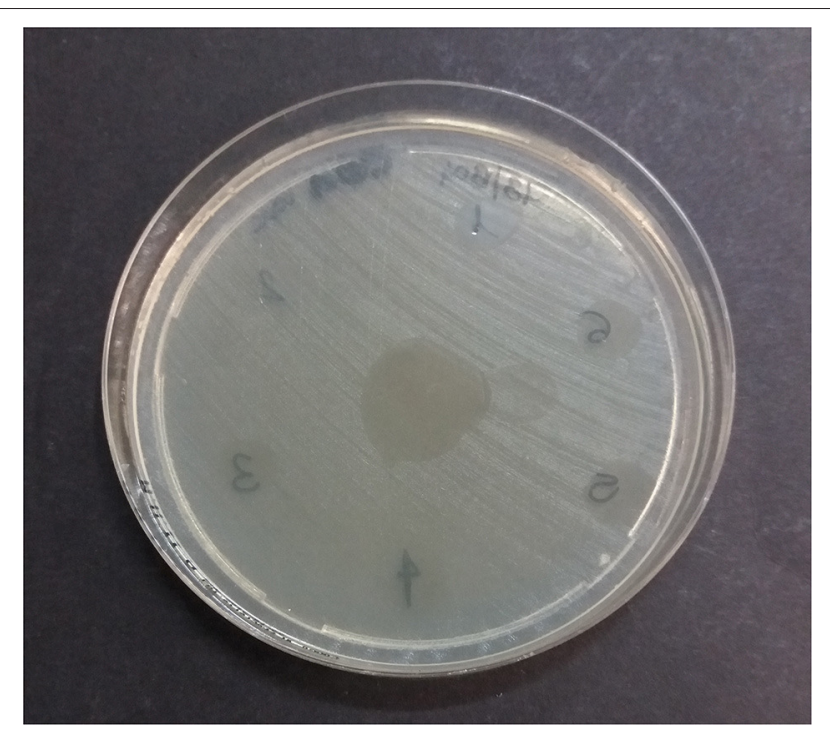

FIGURE 2 | Multidrug-resistant $K$. pneumoniae ssp. pneumoniae inhibition zones by leukocyte-formulations after $4 \mathrm{~h}$ at $37^{\circ} \mathrm{C}$ aerobically. 1: platelet lysate; 2: thrombin; 3: L-PRP; 4: L-PRP plus thrombin; 5: L-PRP plus calcium gluconate; 6: L-PPP; in the center of the plate: L-PG.

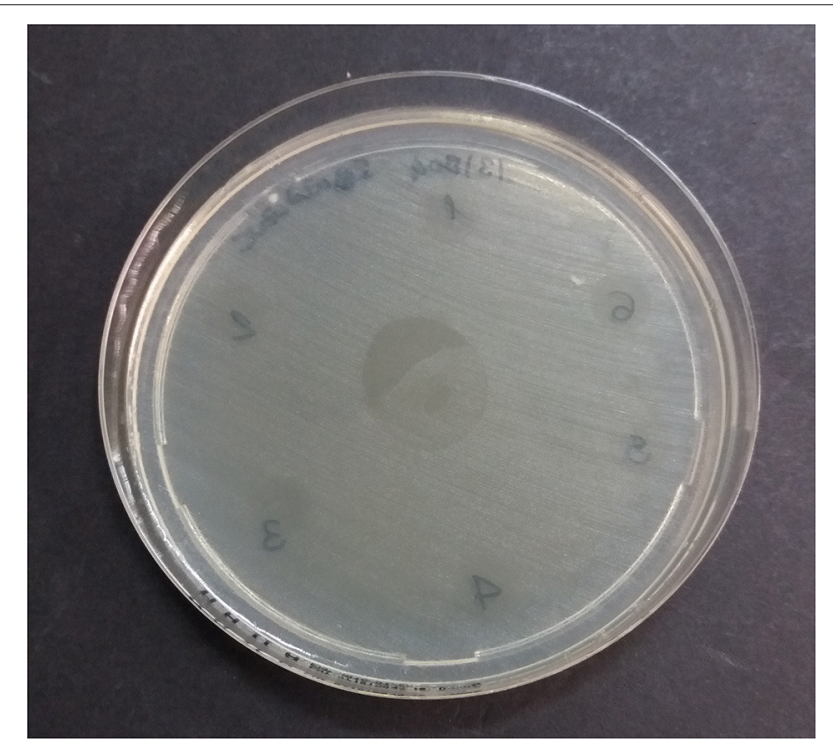

FIGURE 3 | Multidrug-resistant $K$. pneumoniae ssp. pneumoniae inhibition zones by pure formulations after $4 \mathrm{~h}$ at $37^{\circ} \mathrm{C}$ aerobically. 1 : fibrin glue; 2 : calcium gluconate; 3: P-PRP; 4: P-PRP plus thrombin; 5: P-PRP plus calcium gluconate; 6: P-PPP; in the center of the plate: P-PG.

The L-PG $500 \mu$ l showed an antibacterial effect against the pan drug-resistant $P$. aeruginosa by recording an inhibition zone of $16.5 \times 43 \mathrm{~mm}$. Moreover, all the hemo-components gave areas of bacterial inhibition, except for thrombin and L-PRP with calcium gluconate against the extensively drug-resistant $E$. coli strain, while P-PPP and P-PG $35 \mu \mathrm{l}$, P-PG $500 \mu \mathrm{l}$, and L-PG $500 \mu \mathrm{l}$ inhibited the growth of MDR and susceptible E. coli.

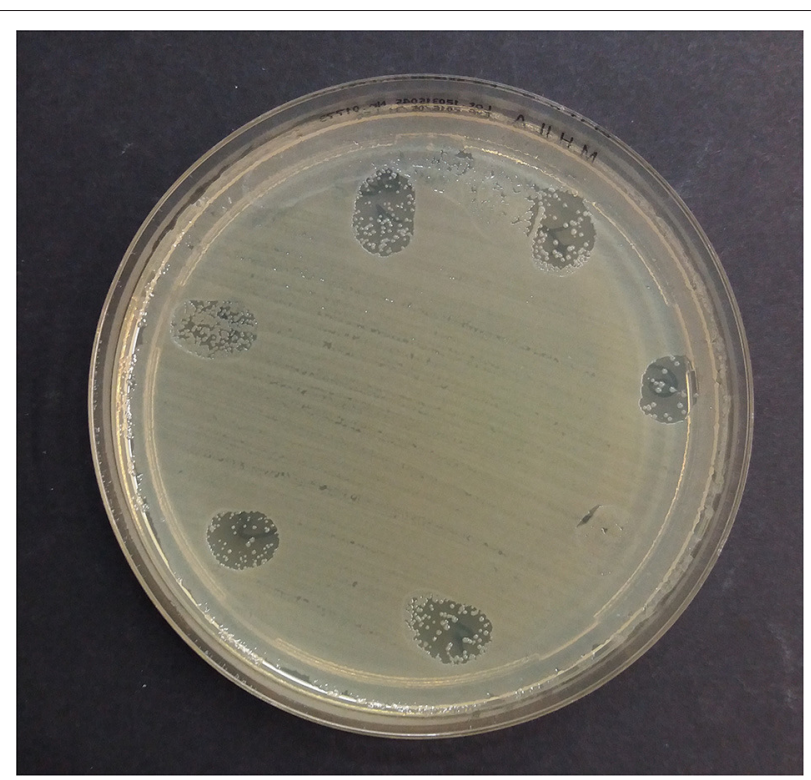

FIGURE 4 | Leukocyte-formulations against the extensively resistant $E$. coli after $18 \mathrm{~h}$ at $37^{\circ} \mathrm{C}$ aerobically. 1: platelet lysate; 2 : thrombin; 3: L-PRP; 4 : L-PRP plus thrombin; 5: L-PRP plus calcium gluconate; 6: L-PPP; 7: L-PG.

The spectrophotometer reading after $18 \mathrm{~h}$ confirmed what was recorded after $4 \mathrm{~h}$ of incubation and revealed more defined inhibition zones. In particular, compared to the respective bacterial positive control, significantly reduced areas of bacterial growth $(p<0.05)$ were observed for the hemo-components against Gram-negative strains (Figure 4, Table 4).

After $18 \mathrm{~h}$ of incubation, L-PG $35 \mu \mathrm{l}$, L-PG $500 \mu \mathrm{l}$, and P-PG $500 \mu \mathrm{l}$ also showed a significant antibacterial effect $(p<0.05)$ against Gram-positive bacteria. Inhibition zones of $4 \times 10 \mathrm{~mm}$, $19 \times 26 \mathrm{~mm}$, and $50 \times 22 \mathrm{~mm}$ were recorded for susceptible S. aureus ssp. aureus in the presence of L-PG $35 \mu \mathrm{l}$, L-PG 500 $\mu \mathrm{l}$, and P-PG $500 \mu \mathrm{l}$, respectively. S. cohnii ssp. cohnii susceptible to the panel of antibiotics tested resulted to be inhibited by P-PG $500 \mu \mathrm{l}(4 \times 17.5 \mathrm{~mm})$.

At $24 \mathrm{~h}$, the size of each inhibition zones was confirmed.

\section{Antibacterial Evaluation by Broth Inhibition by Microtiter Method}

Reductions in bacterial growth (mean $\mathrm{OD}_{540 \mathrm{~nm}}$ values) were also recorded with the microtiter method, as early as $4 \mathrm{~h}$ for Gram-negative microorganisms. This was confirmed by reading at 18 and $24 \mathrm{~h}$. In relation to Gram affinity, different hemocomponents induced a significant decrease in the growth of Gram-negative $(0.897$ vs. $1.604, \mathrm{t}=3.537 p=0.001)$ and resistant bacteria ( 0.742 vs. $1.908, \mathrm{t}=4.506 p=0.0005)$ compared with the corresponding bacterial growth in the absence of the hemocomponent. At $18 \mathrm{~h}$, thrombin significantly reduced the MDR $P$. aeruginosa growth $(1.845$ vs. $2.258, \mathrm{t}=41.094 p=0.0001)$. The presence of leukocytes inhibited the bacterial growth more, but not statistically significant, compared with hemo-components without leukocytes. Significant differences were observed for 
TABLE 4 | Inhibition zones (mm) recorded for Gram-negative bacteria after $18 \mathrm{~h}$ of incubation using the Kirby-Bauer method.

\begin{tabular}{|c|c|c|c|c|c|c|}
\hline \multirow[t]{3}{*}{ Hemo-components } & \multicolumn{6}{|c|}{ Inhibition zones (mm) } \\
\hline & \multicolumn{2}{|c|}{ K. pneumoniae } & \multicolumn{2}{|c|}{ E. coli } & \multicolumn{2}{|c|}{ P. aeruginosa } \\
\hline & MDR & XDR & MDR & XDR & MDR & PDR \\
\hline Platelet lysate & $9 \times 10$ & & $13 \times 9$ & & $5 \times 4$ & $9 \times 6$ \\
\hline Fibrin glue & & & & $8 \times 10$ & & $8 \times 10$ \\
\hline Thrombin & & & & & $8 \times 8$ & $5 \times 5$ \\
\hline L-PRP & & $9 \times 8$ & $8.5 \times 10.5$ & & $5.5 \times 7$ & $8.5 \times 9.5$ \\
\hline P-PRP & & $9 \times 9$ & & & $8 \times 10$ & \\
\hline L-PRP plus thrombin & $9 \times 9$ & & & $9 \times 12.5$ & $6.5 \times 6$ & $7 \times 7$ \\
\hline P-PRP plus thrombin & $9 \times 9$ & & $8 \times 10$ & & & \\
\hline P-PRP plus calcium gluconate & & & $8 \times 10$ & & & \\
\hline L-PRP plus calcium gluconate & $8 \times 9$ & & $10 \times 11$ & & $4 \times 4.5$ & $6.5 \times 7$ \\
\hline L-PPP & & $9 \times 9.5$ & $8.5 \times 10.5$ & & $5 \times 7$ & $8 \times 9.5$ \\
\hline P-PPP & & $9 \times 9$ & $8 \times 10$ & $6.5 \times 8$ & & \\
\hline L-PG $35 \mu \mathrm{l}$ & $19 \times 20$ & $9 \times 10$ & & $11 \times 10$ & $10.5 \times 18$ & $11 \times 12$ \\
\hline P-PG $35 \mu 1$ & $8 \times 18$ & & & & & \\
\hline L-PG $500 \mu l$ & $38 \times 45$ & $19 \times 20$ & $18.5 \times 10.5$ & $16 \times 10$ & $20.5 \times 20$ & $21 \times 22$ \\
\hline P-PG $500 \mu \mathrm{l}$ & $28 \times 64$ & & & & & \\
\hline
\end{tabular}

L-PRP, leukocyte platelet-rich plasma; P-PRP, pure platelet-rich plasma; L-PPP, leukocyte platelet-poor plasma; P-PPP, pure platelet-poor plasma; L-PG, leukocyte platelet gel; P-PG, pure platelet gel.

MDR, XDR K. pneumoniae, E. coli, XDR, and PDR P. aeruginosa (Table 5).

No significant bacterial reductions were observed when PPRP, L-PRP, and P-PRP with thrombin, L-PRP and P-PRP with calcium gluconate, and L-PG $10 \mu \mathrm{l}$ and P-PG $10 \mu \mathrm{l}$ were applied for 18 and $24 \mathrm{~h}$.

For Gram-positive bacteria, $\mathrm{OD}_{540 \mathrm{~nm}}$ reductions were observed at $18 \mathrm{~h}$ for all $S$. aureus ssp. aureus strains in the presence of FG (1.025 vs. $1.439, \mathrm{t}=114.969 p=0.0001)$ and $24 \mathrm{~h}$ (1.153 vs. $\left.1.553, \mathrm{t}=222.159 p<10^{-4}\right)$ in comparison to the positive controls.

L-PG $10 \mu \mathrm{l}$ reduced MDR S. aureus ssp. aureus, both at $18 \mathrm{~h}\left(1.15\right.$ vs. $\left.1.481, \mathrm{t}=160.803 p<10^{-4}\right)$ and at $24 \mathrm{~h}$ (0.665 vs. $\left.0.9765, \mathrm{t}=278.611 p<10^{-4}\right) . \mathrm{L}-\mathrm{PG} 20 \mu \mathrm{l}(0.622$ vs. $0.955, \mathrm{t}=7.8347 p=0.0159)$, L-PG $180 \mu \mathrm{l}(-0.018$ vs. $0.955, \mathrm{t}=46.344 p=0.0005)$, and P-PG $180 \mu \mathrm{l}(-0.4055$ vs. $0.955, \mathrm{t}=11.783 p=0.007)$ were able to reduce $\mathrm{XDR}$ $S$. aureus ssp. aureus growth. Similar significant reductions were confirmed for the P-PG $180 \mu \mathrm{l}$ at $24 \mathrm{~h}(-0.354$ vs. $0.976, \mathrm{t}=1.2$ $\left.p<10^{-4}\right)$.

For hemo-components such as PL, FG, and thrombin, comparison of the mean ODs recorded at 18 and $24 \mathrm{~h}$ for all groups of bacteria showed a non-significant increase, except for FG for resistant bacteria, for which there was a reduction, although not significant.

By the broth microdilution method, non-transfusional hemocomponents with and without leukocytes showed similar bacterial properties toward all bacterial strains tested, although a greater but not significant reduction was observed for LPG $180 \mu \mathrm{l}$, at both $18 \mathrm{~h}(p=0.252)$ and $24 \mathrm{~h}(p=0.306)$ (Figures 5-8).

\section{DISCUSSION AND CONCLUSIONS}

Several studies have been conducted recently, mainly in human medicine, to demonstrate the antimicrobial effect of nontransfusional hemo-components for topical use.

Few studies have been performed in vitro regarding the potential antimicrobial effect of animal hemo-components (31, 51-53). One study showed antibacterial activity of thrombinactivated platelets in horses (51). Platelet-rich plasma from rabbits had strong in vitro antimicrobial properties against methicillin-susceptible and methicillin-resistant Staphylococcus aureus, Group A Streptococcus, and Neisseria gonorrhoeae (53). Moreover, Lopez evidenced a bacteriostatic effect of equine pure platelet-rich formulations (31). In addition, antibiofilm properties of equine platelet-rich plasma lysate were also highlighted (52).

Some in vivo experimental studies using animal models have also confirmed the potential antimicrobial effect of non-transfusional hemo-components $(57,61-63,66)$. Plateletrich plasma showed antimicrobial properties in rabbit models of osteomyelitis $(61,62)$ and postoperative spinal implantassociated infections (63). Platelet-rich plasma improved healing of experimentally infected surgical wounds in rats (57) and accelerated healing of canine skin wounds by exerting antibacterial activity, rapid reduction of inflammation, rapid re-epithelialization, and granulation tissue formation (66).

Based on this literature evidence on animals, this study assessed the antimicrobial activity of different hemo-components for non-transfusional use obtained from canine species against bacteria with different characteristics. To the authors' knowledge, this study represents the first steps conducted in vitro to evaluate 
TABLE 5 | OD $540 \mathrm{~nm}$ reductions in Gram-negative bacteria (mean $\mathrm{OD}_{540 \mathrm{~nm}}$ bacterium plus hemo-component vs. mean $\mathrm{OD}_{540 \mathrm{~nm}}$ bacterial control) recorded after 18 and $24 \mathrm{~h}$ of incubation by the broth microdilution method.

\begin{tabular}{|c|c|c|c|c|c|c|c|}
\hline \multirow[t]{3}{*}{ Hemo-components } & \multirow[t]{3}{*}{ Time (h) } & \multicolumn{6}{|c|}{$\mathrm{OD}_{540 \mathrm{~nm}}$} \\
\hline & & \multicolumn{2}{|c|}{ K. pneumoniae } & \multicolumn{2}{|c|}{ E. coli } & \multicolumn{2}{|c|}{$P$ aeruginosa } \\
\hline & & MDR & XDR & MDR & XDR & MDR & PDR \\
\hline \multirow[t]{2}{*}{ Bacterial controls without hemo-components } & 18 & 1.195 & 1.300 & 1.432 & 1.568 & 2.258 & 2.641 \\
\hline & 24 & 1.413 & 1.440 & 1.512 & 1.338 & 2.340 & 2.653 \\
\hline \multirow[t]{2}{*}{ Fibrin glue } & 18 & & & & 1.366 & & \\
\hline & 24 & & & & $0.9322^{* 1}$ & & \\
\hline \multirow[t]{2}{*}{ Thrombin } & 18 & & & & & $1.845^{* 2}$ & \\
\hline & 24 & & & & & $1.633^{\star 3}$ & \\
\hline \multirow[t]{2}{*}{ L-PRP } & 18 & & 1.290 & & 1.498 & 2.002 & $2.230 * 4$ \\
\hline & 24 & & & & $0.978^{* 5}$ & & $2.116^{*} 6$ \\
\hline \multirow[t]{2}{*}{ P-PRP } & 18 & & 1.110 & & & 2.010 & \\
\hline & 24 & & 1.268 & & & 2.100 & \\
\hline \multirow[t]{2}{*}{ L-PRP plus thrombin } & 18 & 1.123 & & & 1.448 & 2.200 & 2.640 \\
\hline & 24 & 1.220 & & & & & \\
\hline \multirow[t]{2}{*}{ P-PRP plus thrombin } & 18 & 1.104 & & 1.398 & & & \\
\hline & 24 & 1.300 & & 1.400 & & & \\
\hline \multirow[t]{2}{*}{ L-PRP plus calcium gluconate } & 18 & 0.901 & & 1.400 & & 2.188 & 2.500 \\
\hline & 24 & 1.290 & & 1.480 & & 2.200 & 2.512 \\
\hline \multirow[t]{2}{*}{ P-PRP plus calcium gluconate } & 18 & & & 1.369 & & & \\
\hline & 24 & & & 1.408 & & & \\
\hline \multirow[t]{2}{*}{ L-PPP } & 18 & & 1.124 & $0.023^{\star 7}$ & & & $2.061^{* 8}$ \\
\hline & 24 & & & & & & $2.019 * 9$ \\
\hline \multirow[t]{2}{*}{ P-PPP } & 18 & & 1.180 & $0.035{ }^{* 10}$ & 1.014 & & $2.260{ }^{*} 11$ \\
\hline & 24 & & & & & & $2.282^{*} 12$ \\
\hline L-PG $10 \mu \mathrm{l}$ & 18 & & & & & & \\
\hline P-PG $10 \mu \mathrm{l}$ & 24 & & & & & & \\
\hline L-PG $20 \mu \mathrm{I}$ & 18 & $1.101^{* 13}$ & & & & & \\
\hline P-PG $20 \mu \mathrm{I}$ & 24 & & & & & & \\
\hline \multirow[t]{2}{*}{ L-PG $40 \mu \mathrm{l}$} & 18 & 0.911 & 1.144 & $1.103^{* 14}$ & & 2.134 & 2.568 \\
\hline & 24 & & & $1.104 * 15$ & $0.970 * 16$ & & \\
\hline \multirow[t]{2}{*}{ P-PG $40 \mu \mathrm{l}$} & 18 & 0.969 & & & $1.099 * 17$ & & $2.328{ }^{*} 18$ \\
\hline & 24 & & & $1.1766^{* 19}$ & $1.2366^{* 20}$ & & \\
\hline \multirow[t]{2}{*}{ L-PG $180 \mu \mathrm{l}$} & 18 & $0.449^{* 21}$ & $1.068^{*} 22$ & $0.345^{* 23}$ & $0.265^{* 24}$ & $1.1966^{* 25}$ & $0.357^{*} 26$ \\
\hline & 24 & $0.480 * 27$ & & $0.350 * 28$ & $0.272^{*} 29$ & $1.926{ }^{*} 30$ & $1.029 * 31$ \\
\hline \multirow[t]{2}{*}{ P-PG $180 \mu \mathrm{l}$} & 18 & $0.505^{* 32}$ & & $0.085^{\star 33}$ & & $1.12^{* 34}$ & $0.643^{* 35}$ \\
\hline & & $0.466^{*} 36$ & $1.006 * 37$ & $0.003^{\star} 38$ & $0.0633^{*} 39$ & $1.007^{*} 40$ & $1.355^{*} 41$ \\
\hline
\end{tabular}

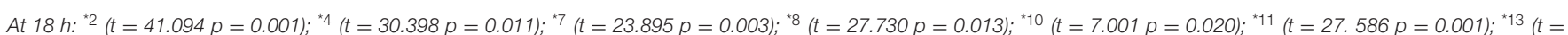

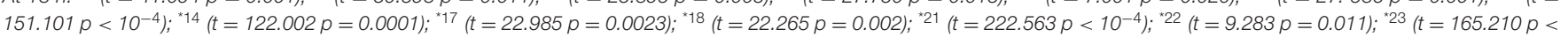

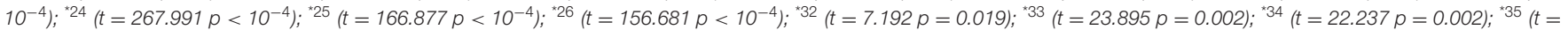
$31.988 p=0.001)$.

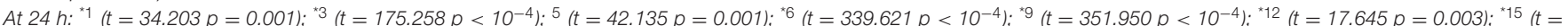

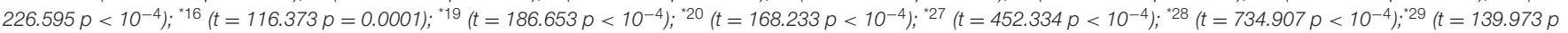

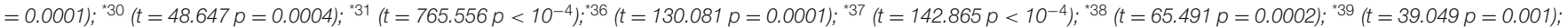

${ }^{* 40}(t=32.126 p=0.001) ;{ }^{* 41}\left(t=181.383 p<10^{-4}\right)$.

the potential inhibitory effect of canine non-transfusional hemocomponents on bacteria collected from canine wounds and classified according to the sensitivity/resistance spectrum toward a known panel of human and veterinary antibiotics.

Although this study was performed on a pool of WB from a limited number of dogs, the results will potentially contribute to enrich the knowledge on this topic, in order to provide some answers to important questions recently posed by different schools of thought.

The action of the hemo-components has been evaluated against Gram-positive bacteria ( $S$. aureus ssp. aureus, $S$. cohnii ssp. cohnii) and Gram-negative (P. aeruginosa, 


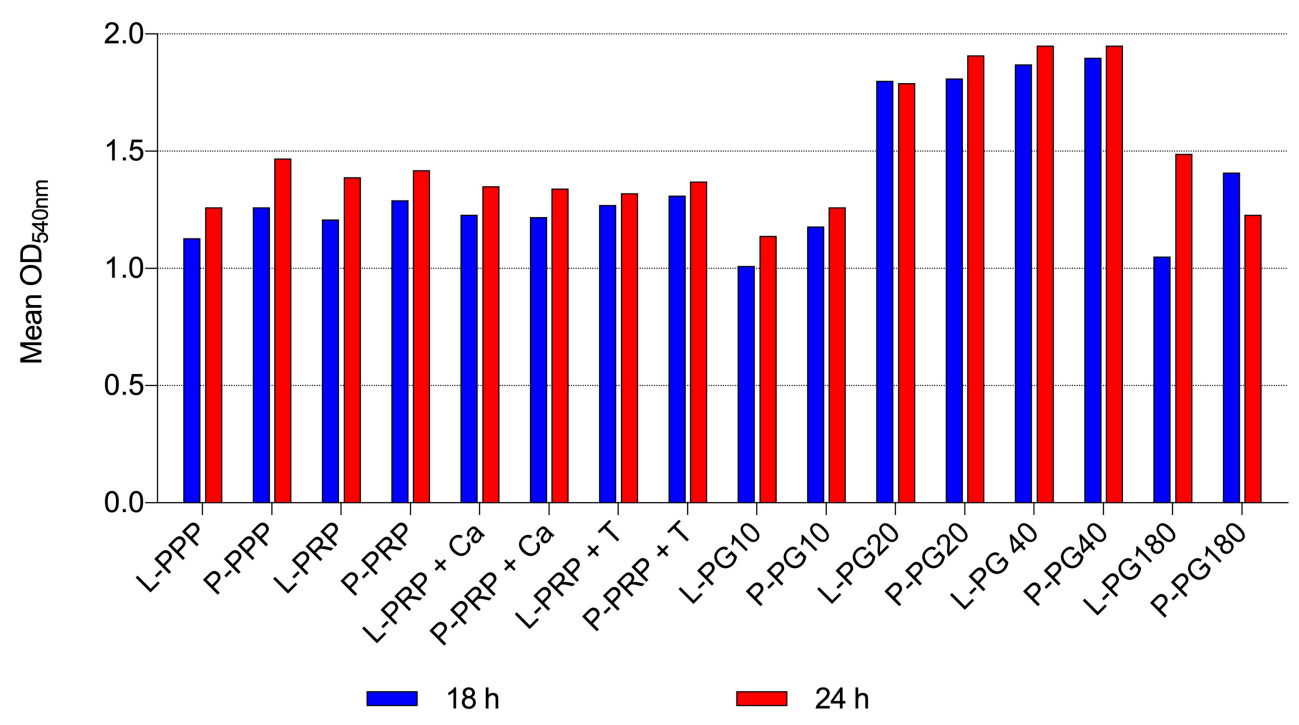

FIGURE 5 | Mean OD $540 \mathrm{~nm}$ values of Gram-positive bacteria observed after 18 and $24 \mathrm{~h}$ of incubation in presence of different non-transfusional hemo-components. L-PPP, leukocyte platelet-poor plasma; P-PPP, pure platelet-poor plasma; L-PRP, leukocyte platelet-rich plasma; P-PRP, pure platelet-rich plasma; L-PRP + Ca, leukocyte platelet-rich plasma with calcium gluconate; P-PRP + Ca, pure platelet-rich plasma with calcium gluconate; L-PRP + T, leukocyte platelet-rich plasma with thrombin-rich solution; P-PRP + T, pure platelet-rich plasma with thrombin-rich solution; L-PG10, leukocyte platelet gel $10 \mu$; P-PG10, pure platelet gel 10 $\mu$ l; L-PG20, leukocyte platelet gel $20 \mu$ l; P-PG20, pure platelet gel $20 \mu$ l; L-PG40, leukocyte platelet gel $40 \mu$ l; P-PG40, pure platelet gel $40 \mu$ l; L-PG180, leukocyte platelet gel $180 \mu \mathrm{l}$; P-PG180, pure platelet gel $180 \mu \mathrm{l}$.

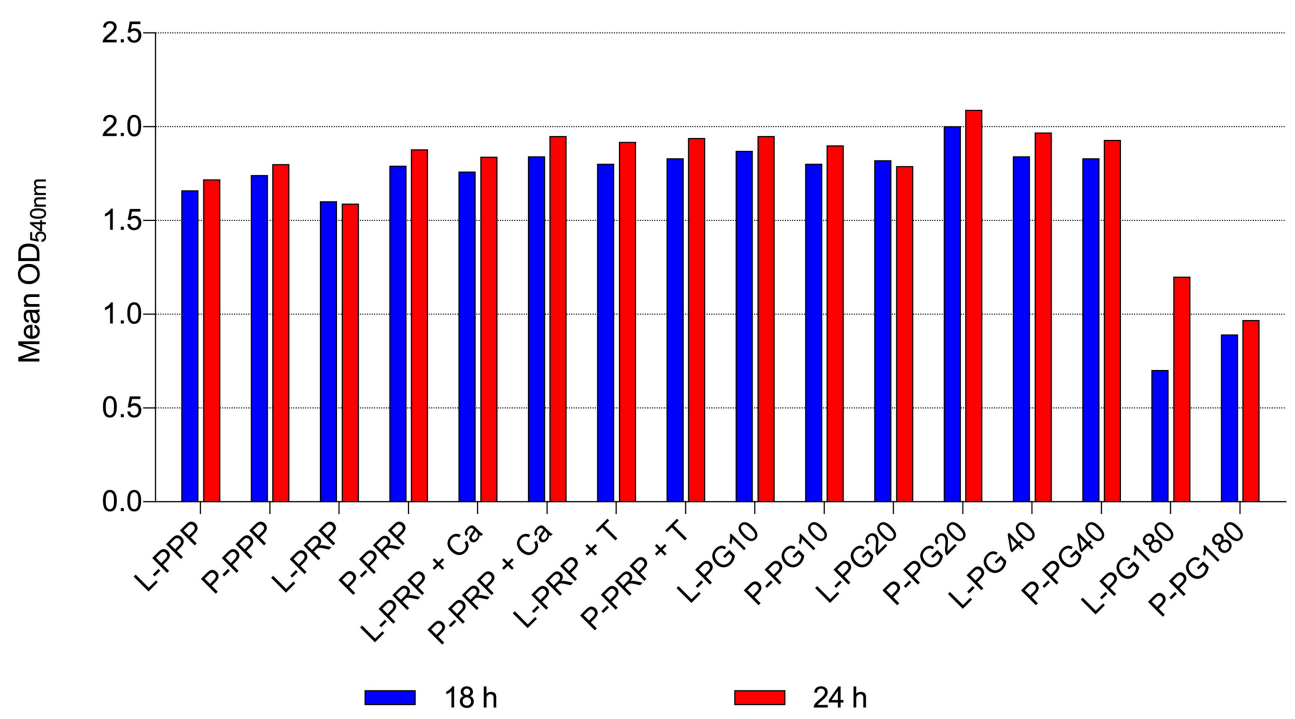

FIGURE 6 | Mean OD $_{540 \mathrm{~nm}}$ values of Gram-negative bacteria observed after 18 and $24 \mathrm{~h}$ of incubation in the presence of different non-transfusional hemo-components. L-PPP, leukocyte platelet-poor plasma; P-PPP, pure platelet-poor plasma; L-PRP, leukocyte platelet-rich plasma; P-PRP, pure platelet-rich plasma; L-PRP + Ca, leukocyte platelet-rich plasma with calcium gluconate; P-PRP + Ca, pure platelet-rich plasma with calcium gluconate; L-PRP + T, leukocyte platelet-rich plasma with thrombin-rich solution; P-PRP + T, pure platelet-rich plasma with thrombin-rich solution; L-PG10, leukocyte platelet gel 10 $\mu$ l; P-PG10, pure platelet gel $10 \mu$ l; L-PG20, leukocyte platelet gel $20 \mu$ l; P-PG20, pure platelet gel $20 \mu$ l; L-PG40, leukocyte platelet gel $40 \mu$ l; P-PG40, pure platelet gel $40 \mu$ l; L-PG180, leukocyte platelet gel $180 \mu$ l; P-PG180, pure platelet gel $180 \mu \mathrm{l}$.

E. coli, K. pneumoniae ssp. pneumoniae) isolated from biological samples of canine origin and previously classified as susceptible, resistant, or MDR to a panel of known antibiotics.
The potential antibacterial effect of the hemo-components has been evaluated by both agar gel diffusion (Kirby-Bauer), and broth inhibition using microtiter plates with spectrophotometer readings at a wavelength of $540 \mathrm{~nm}\left(\mathrm{OD}_{540 \mathrm{~nm}}\right)$. PL, FG, 


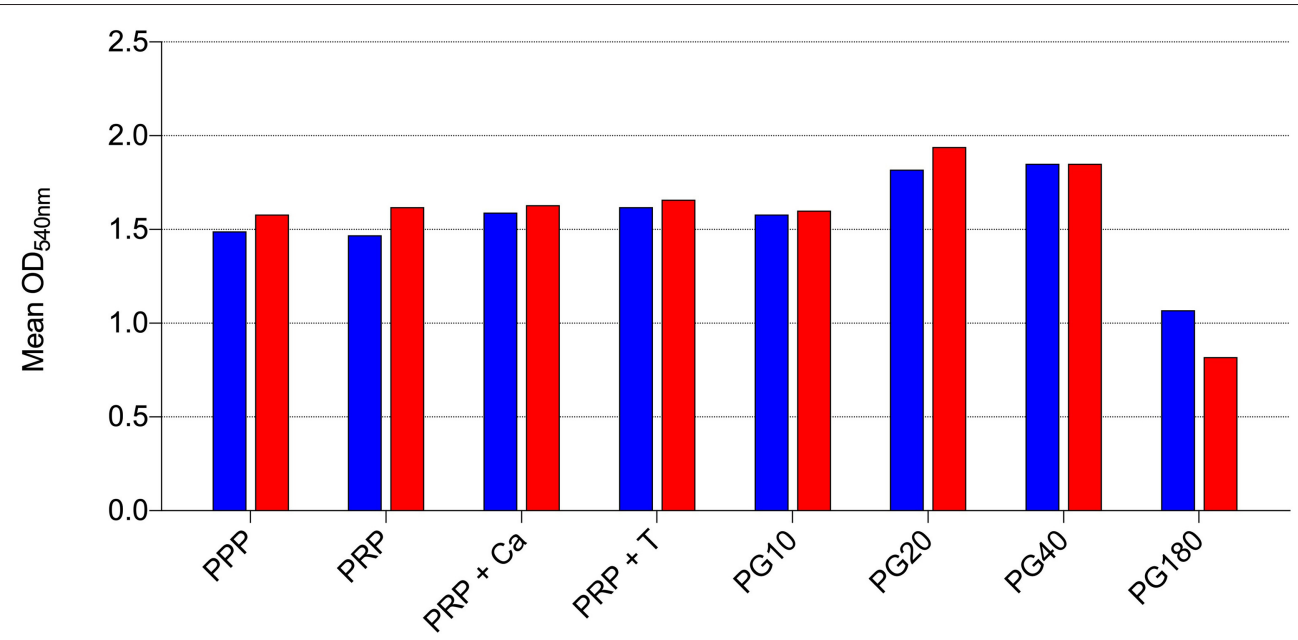

Leucocyte-rich formulations

Leucocyte-poor formulations

FIGURE 7 | Mean $\mathrm{OD}_{540 \mathrm{~nm}}$ values of leukocyte-rich formulations and leukocyte-poor formulations observed after $18 \mathrm{~h}$ of incubation in the presence of different non-transfusional hemo-components. PPP, platelet-poor plasma; PRP, platelet-rich plasma; PRP + Ca, platelet-rich plasma with calcium gluconate; PRP + T, platelet-rich plasma with thrombin-rich solution; PG10, platelet gel $10 \mu$ l; PG20, platelet gel $20 \mu$ l; PG40, platelet gel $40 \mu$; PG180, platelet gel 180 $\mu$ l.

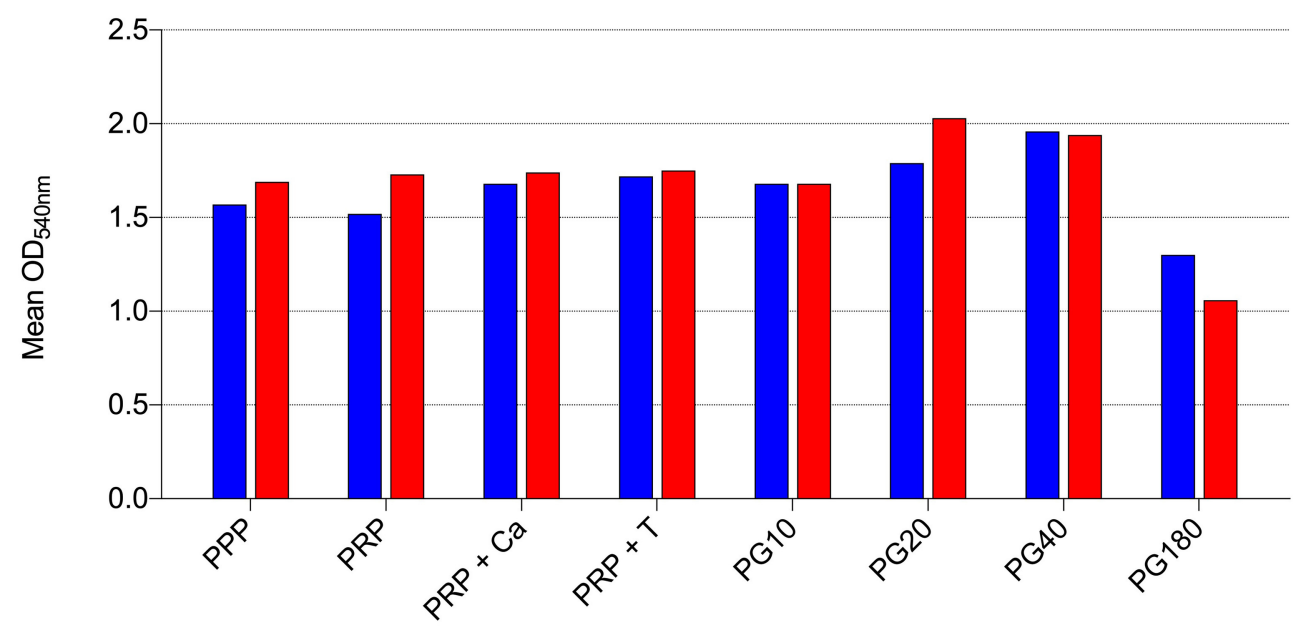

Leucocyte-rich formulations

Leucocyte-poor formulations

FIGURE 8 | Mean $\mathrm{OD}_{540 \mathrm{~nm}}$ values of leukocyte-rich formulations and leukocyte-poor formulations observed after $24 \mathrm{~h}$ of incubation in the presence of different non-transfusional hemo-components. PPP, platelet-poor plasma; PRP, platelet-rich plasma; PRP + Ca, platelet-rich plasma with calcium gluconate; PRP + T, platelet-rich plasma with thrombin-rich solution; PG10, platelet gel $10 \mu$; PG20, platelet gel $20 \mu$ l; PG40, platelet gel $40 \mu$; PG180, platelet gel 180 $\mu$ l.

and thrombin-rich solution were tested for the first time in veterinary medicine.

WB from dogs with degenerative joint disease who underwent intra-articular therapy with autologous PRP was used in this study; this choice was mainly determined by ethical reasons, but it also allowed us to be more adherent to daily clinical practice. To limit the impact of individual donor variations, as performed in other studies, a pool was created with WB collected from all dogs and all materials tested were obtained from the same pool of dogs $(36,48,52)$.

In this study, the cell counts contributed to define the quality of hemo-components preparation procedures, supporting the hypothesis of some authors who relate the platelet concentration to the clinical regenerative effect as it is positively correlated with the concentration of growth factors (7375). Conversely, an excessively high platelet concentration is 
considered counterproductive to the healing process, as it has the potential to inhibit the angiogenic process (76). The platelet fold increase from WB and the platelet concentration obtained in the final product could be considered rough measures to define the quality of the production process and of the PRP for clinical use, respectively (77).

Specifically, the platelet concentration in L-PRP was similar to what Mazzucco et al. considered a "reasonable compromise" for determining the quality of the PCs for regenerative medicine therapeutic purposes $(77,78)$.

Increases in platelet and leukocyte concentrations in PRP compared with baseline concentration in WB were similar to those obtained by Perego et al. (79).

Platelet and leukocyte contents in P-PRP were comparable to those in other studies (42).

Platelet and leukocyte concentrations were much lower (45fold and 140-fold, respectively) in L-PPP than the L-PRP formulation, similarly to Burnouf who obtained a 50-fold decrease in leukocytes and a 100-fold decrease in platelets (45).

The potential antimicrobial role of leukocytes and platelets was evaluated by comparing the bacterial load (OD) inhibition values for PPP, PRP, PRP with calcium gluconate, PRP with thrombin, and PG in various amounts, in both leukocyte-rich formulations and leukocyte-poor (or pure) formulations. PPP, although rarely used in regenerative medicine for therapeutic purposes, has been tested to define the innate antimicrobial role of plasma or humoral immune response: the result of our study suggests that the antimicrobial bacteriostatic action, especially against Gram-negative bacteria, might be related to plasma components rather than the platelets. In this study, the presence of leukocytes has been shown not to be significant for the antimicrobial activity of hemo-components, although in the presence of leukocytes a reduction in growth was observed for a greater number of microorganisms than in the action of hemo-components without leukocytes. The effect of leukocytes in PCs is the focus of heated scientific debate. Many authors have suggested that the addition of white blood cells could enhance the antibacterial potential (47, 8082). However, Anitua and collaborators have shown that the addition of leukocytes does not significantly improve the strong antibacterial properties. It is also possible that leukocytes could increase the inflammatory response at the site because they secrete metalloproteinases, pro-inflammatory proteases, and acid hydrolases (42). Other authors agree that the presence of leukocytes does not increase the antibacterial effect of PCs (31$33,83)$. In our study, the presence of leukocytes is confirmed to be non-significant for the antimicrobial activity of nontransfusional hemo-components.

By the Kirby-Bauer method, the antibacterial effect of platelet gel (PG), both with and without leukocytes, has been documented as early as $4 \mathrm{~h}$ for some bacteria, confirmed at $18 \mathrm{~h}$, especially for slow-growing bacteria, and remained constant until $24 \mathrm{~h}$. Results obtained by the agar gel diffusion method (Kirby-Bauer) were confirmed by broth inhibition using microtiter plates and reading by spectrophotometry. Both L-PG and P-PG showed a reduction in the bacterial load of Gram-negative bacteria, also PDR P. aeruginosa.
Studies using the broth inhibition method did not agree with the observed results. Edelblute et al. showed no antibacterial activity of PG against $P$. aeruginosa, while significant bactericidal activity was observed against $S$. aureus and Acinetobacter baumannii (49). Drago et al. showed a lack of action of PPRP, against $P$. aeruginosa; on the contrary, growth inhibition was recorded for Gram-positive and yeasts: E. faecalis, Candida albicans, Streptococcus agalactiae, and Streptococcus oralis (30).

Zones of inhibition were observed with L-PG, at the amount of $35 \mu \mathrm{l}$ in both MDR Gram-negative microorganisms (K. pneumoniae ssp. pneumoniae, P. aeruginosa, and E. coli) and susceptible Gram-positive bacteria. In one study, $30 \mu \mathrm{l}$ of L-PG induced, after $3 \mathrm{~h}$ and up to $48 \mathrm{~h}$, a significant growth inhibition effect for K. pneumoniae, P. aeruginosa, E. coli, and S. aureus (45).

The results of our study are partly consistent with those described by Bielecki et al. who observed growth inhibition of E. coli and methicillin-susceptible and methicillin-resistant $S$. aureus strains with L-PG $12 \mu \mathrm{l}$. The measured inhibition zones were comparable to those of gentamicin and oxacillin, analog of methicillin (28). In contrast to our study, the same authors did not observe a reduction for $K$. pneumoniae and $P$. aeruginosa (28).

As the amount of PG tested increased, the inhibitory effect on bacteria also increased, because of the observed reduction in bacterial load. L-PG $500 \mu$ l decreased the growth of all microorganisms, except for methicillin-susceptible $S$. aureus ssp. aureus strain.

The potential antibacterial effect of leukocyte-poor or pure platelet gel (P-PG) was also tested in this study. At the amount of $35 \mu \mathrm{l}, \mathrm{P}-\mathrm{PG}$ already showed an area of growth inhibition exclusively for multiresistant K. pneumoniae ssp. pneumoniae, whereas at the amount of $500 \mu \mathrm{l}$ P-PG showed growth inhibition for more types of bacteria: this effect was observed for all bacterial strains except MDR P. aeruginosa and S. conhii ssp. cohnii.

Inhibitory action was also observed for formulations in the pre-activation phase (L-PRP, PRP-P), although not against Grampositive bacteria.

In the inhibition zones, characterized by lower growth halos, a bacteriostatic action can be assumed, as for some antibiotic drugs.

A recent systematic review also observed a tendency of PCs to inhibit the growth of microorganisms during the first hours of incubation, whereas they did not seem to be able to completely break down the microbial load, indicating a bacteriostatic rather than a bactericidal activity (56).

On this aspect, in the presence of thrombin-activated PRP, Wu et al. observed a reduction in the number of E. coli, $P$. aeruginosa, and $K$. pneumoniae during the first 8 to $12 \mathrm{~h}$, with the greatest reduction observed at 0 to $4 \mathrm{~h}$. The number of bacteria increased again after the 4 -h time point because the bacterial killing process was not complete; after this time point, bacterial growth exceeded the killing rate and growth continued until the stationary phase was reached at the 24 -h time point (47).

It is interesting to note that PL, FG, and thrombin had an inhibitory action only against Gram-negative bacteria. This finding could open up innovative therapeutic possibilities, potentially exploiting combined therapies in a clinical scenario with infections sustained by these types of bacteria, sometimes 
rather aggressive and difficult to treat. Specifically, thrombin at the amount of $8 \mu \mathrm{l}$ was able to create a visible zone of reduced growth for the two P. aeruginosa strains (MDR and PDR). The only strain of $S$. aureus ssp. aureus (susceptible to the panel of antibiotics) whose bacterial load was significantly decreased by FG was also moderately inhibited by PL and thrombin. Although studies on these hemo-components are very few in the literature, our findings are in contrast to Bielecki and collaborators who observed no inhibitory effect using $12 \mu \mathrm{l}$ of thrombin against $S$. aureus, E. coli, K. pneumoniae, P. aeruginosa, and E. faecalis (28).

Other studies have shown that activation of platelets in PRP with thrombin leads to a significant increase in inhibitory activity on bacteria (51). In the same study, addition of thrombin to E. coli was shown not to affect bacterial growth, and addition of thrombin to PPP did not increase the inhibitory effect (51).

Although further studies will need to be done to clarify the mechanism of action, the thrombin-rich solution used in our study may have had antibacterial action by itself, because it is derived from autologous plasma, and it is not thrombin derived from complex chemical extraction.

Some studies have tested the potential link between the antibacterial effect and the platelet activation process with $\mathrm{CaCl}_{2}$, reaching discordant results $(45,48)$. According to Burnouf et al., activation of coagulation to prepare PG may reduce antimicrobial activity by consuming complement or other inhibitors or by releasing components that support bacterial proliferation (45). Contrariwise, Drago et al. observed that only activated materials were able to inhibit bacterial growth, suggesting that the activation of coagulation is a key step (48).

The antibacterial action against Gram-negative bacteria, observed for L-PPP, P-PPP, L-PRP, and P-PRP and the same with the addition of calcium gluconate and thrombin, is consistent with that documented by Burnouf et al. Using PPP, PRP, and PL, these authors obtained inhibitory action against E. coli, P. aeruginosa, and K. pneumoniae, but not against Grampositive microorganisms, except for S. aureus (45). The zones of inhibition observed in our study showed a minimum area of $4 \times 4.5 \mathrm{~mm}$ in contrast to the zones of inhibition of $0.5,0.5-1$, and $>1 \mathrm{~mm}$ considered by Burnouf et al. (45). Tohidnezhad et al. also observed antibacterial action of PRP with thrombin for E. coli and P. aeruginosa, Enterococcus faecalis, Bacillus megaterium, and Proteus mirabilis (44). Li et al. found that PRP has strong antimicrobial properties in vitro against bacteria such as methicillin-susceptible and methicillin-resistant Staphylococcus aureus, Group A Streptococcus, and Neisseria gonorrhoeae (53).

The bacteriostatic action of the PPP, with and without leukocytes, was shown only for Gram-negative bacteria (E. coli, $P$. aeruginosa, and $K$. pneumoniae ssp. pneumoniae) belonging to the MDR and PDR groups. This finding suggests that the antimicrobial bacteriostatic action might be related to plasma components rather than platelets.

The mechanism of the antibacterial effect of PCs is not yet fully understood.

There are several studies suggesting that platelets play a very important role in the innate defense against the induction and progression of endovascular infections. This host defense capacity depends on the ability of platelets to release a group of antimicrobial peptides, known collectively as platelet protein microbicide, at the site of damage or endovascular infection. Indeed, platelets generate oxygen metabolites, including peroxide, hydrogen peroxide, and free radicals; are able to bind and aggregate microorganisms, improving the clearance of pathogens from the bloodstream; have chemotactic action on macrophages; participate in antibody-dependent cellular cytotoxicity functions against pathogens; and, finally, would release a series of potent antimicrobial peptides $(84,85)$.

In one study, PPP showed no impact on the growth parameters of any of the bacteria tested, whereas PRP showed an antibacterial effect with a strong correlation between platelet concentration and antibacterial activity (38). Mariani et al., instead, showed that both PRP and PPP inhibited bacterial growth for up to $2 \mathrm{~h}$ of incubation, but the effect of P-PRP was significantly higher than that of PPP (32).

One study proposed a possible molecular mechanism to explain the antimicrobial effect of PRP at least against E. coli and $P$. mirabilis through the detection of an antimicrobial peptide in PRP, the human beta-defensin 2 (hBD-2) (44). Another study showed that PCs induced a significant increase in hBD-2 expression in primary keratinocytes cell culture in a concentration- and time-dependent manner (86).

Several antibacterial peptides have also been identified in human platelets, including connective tissue-activating peptide 3 (CTAP-3), platelet factor 4 (PF-4), regulated upon activationnormal T-cell expressed and secreted protein (RANTES), thymosin $\beta-4$ (T $\beta-4)$, platelet basic protein (PBP), fibrinopeptide A (FP-A), and fibrinopeptide B (FP-B) (87-89).

Drago et al. also tested P-PPP against Gram-positive bacteria isolated from the oral cavity obtaining similar, although slightly lower, results to P-PRP, whereas platelets alone showed no antibacterial activity (48). The authors concluded that the antimicrobial activity of PCs against E. faecalis, S. agalactiae, $S$. oralis, and $S$. aureus is supported by a synergy of plasma components and platelet-derived factors (48).

In our study, in relation to the different groups of microorganisms, significant reductions were observed only for Gram-negative MDR bacteria in the presence of PG $180 \mu \mathrm{l}$, both with and without leukocytes. For P-PG $180 \mu$ l, the inhibitory action was also documented for Gram-negative PDR bacteria.

The results of this study are certainly very encouraging and stimulate further studies to understand the mechanism of antibacterial effect. A greater knowledge of the mechanism of action could bring considerable advantages for potential practical applications, being able to better outline the indications, the limits, and the conditions of practical use, also for the antibacterial effect in addition to the consolidated regenerative effect of the non-transfusional hemo-components.

To justify the antibacterial effect of hemo-components, future research can be ideally oriented to the investigation of potential plasma factors, ideally starting from the peptides already identified for the human species but considering that there could be differences between the human and canine species, as evidenced by this study regarding the antibacterial effect. 
Our study confirmed the hypothesized antibacterial properties of canine non-transfusional hemo-components. The bacteriostatic effect appeared to be higher against Gram-negative bacteria. The presence of neither leukocytes nor platelets seems to be essential for the antibacterial effect. Although the interaction of hemo-components with microbial pathogens needs further investigations because the exact mechanism responsible for the antibacterial activity is not yet fully known, non-transfusional hemo-components have been shown to represent a useful natural substance for infection control, especially at surgical sites in the immediate postoperative period. The emergence of multidrug-, extensively drug-, and pan drug-resistant bacteria poses a significant health and economic threat for animals and humans. Therefore, local application of non-transfusional hemo-components could support the action of molecules with antibiotic activity and represent a suitable alternative to control MDR pathogens.

\section{DATA AVAILABILITY STATEMENT}

The raw data supporting the conclusions of this article will be made available by the authors, without undue reservation.

\section{REFERENCES}

1. World Health Organization (WHO). GLASS Whole-Genome Sequencing for Surveillance of Antimicrobial Resistance: Global Antimicrobial Resistance and Use Surveillance System (GLASS). Geneva: World Health Organization (2020). Available online at: https://www.who.int/health-topics/antimicrobialresistance.

2. Cloeckaert A, van Duijkeren E, Schwarz S. Antimicrobial Resistance in Animals and the Environment - ARAE 2015. Vet Microbiol. (2016) 194:1-4. doi: 10.1016/j.vetmic.2016.09.001

3. Görmeli G, Görmeli CA, Ataoglu B, Çolak C, Aslantürk O, Ertem K. Multiple PRP injections are more effective than single injections and hyaluronic acid in knees with early osteoarthritis: a randomized, double-blind, placebocontrolled trial. Knee Surg, Sport Traumatol Arthrosc. (2017) 25:958-65. doi: 10.1007/s00167-015-3705-6

4. Samy AM. The role of platelet rich plasma in management of fracture neck femur: new insights. Int Orthop. (2016) 40:1019-24. doi: 10.1007/s00264-015-2844-1

5. Martini LI, Via AG, Fossati C, Randelli F, Randelli P, Cucchi D. Single plateletrich plasma injection for early stage of Osteoarthritis of the knee. Joints. (2017) 5:2-6. doi: 10.1055/s-0037-1601405

6. Alessio-Mazzola M, Repetto I, Biti B, Trentini R, Formica M, Felli L. Autologous US-guided PRP injection versus us-guided focal extracorporeal shock wave therapy for chronic lateral epicondylitis: a minimum of 2-year follow-up retrospective comparative study. J Orthop Surg. (2018) 26:1-8. doi: $10.1177 / 2309499017749986$

7. Huang $\mathrm{Y}, \mathrm{Liu} \mathrm{X}, \mathrm{Xu} \mathrm{X}$, Liu J. Intra-articular injections of plateletrich plasma, hyaluronic acid or corticosteroids for knee osteoarthritis: a prospective randomized controlled study. Orthopade. (2019) 48:239-47. doi: 10.1007/s00132-018-03659-5

8. Yuksel EP, Sahin G, Aydin F, Senturk N, Turanli AY. Evaluation of effects of platelet-rich plasma on human facial skin. J Cosmet Laser Ther. (2014) 16:206-8. doi: 10.3109/14764172.2014.949274

9. Picard F, Hersant B, Bosc R, Meningaud JP. Should we use platelet-rich plasma as an adjunct therapy to treat "acute wounds," "burns," and "laser therapies": a review and a proposal of a quality criteria checklist for further studies. Wound Repair Regen. (2015) 23:163-70. doi: 10.1111/wrr.12266

\section{ETHICS STATEMENT}

The animal study was reviewed and approved by Animal Welfare Body of the University of Camerino. Written informed consent was obtained from the owners for the participation of their animals in this study.

\section{AUTHOR CONTRIBUTIONS}

A-RA and AT contributed to the conception and design of the study. CI organized the database. ES and AT recruited the animals and prepared the hemo-components. A-RA, CI, AC, and ML performed the bacteriological evaluations. A-RA performed the statistical analysis. A-RA, CI, and AT wrote the first draft of the manuscript. AC, CR, GM, GR, LG, and VC wrote sections of the manuscript. All authors contributed to manuscript revision, read, and approved the submitted version.

\section{FUNDING}

This work was supported by a research grant from the University of Camerino, Italy (Fondo di Ateneo per la Ricerca 2014.2015).

10. Martinez-Zapata MJ, Martí-Carvajal AJ, Solà I, Expósito JA, Bolíbar I, Rodríguez L, et al. Autologous platelet-rich plasma for treating chronic wounds. Cochrane Database Syst Rev. (2016) 5:CD006899. doi: 10.1002/14651858.CD006899.pub3

11. Moneib HA, Youssef SS, Aly DG, Rizk MA, Abdelhakeem YI. Autologous platelet-rich plasma versus conventional therapy for the treatment of chronic venous leg ulcers: a comparative study. J Cosmet Dermatol. (2018) 17:495-501. doi: 10.1111 /jocd.12401

12. Burgos-Alonso N, Lobato I, Hernández I, Sebastian KS, Rodríguez B, March AG, et al. Autologous platelet-rich plasma in the treatment of venous leg ulcers in primary care: a randomised controlled, pilot study. J Wound Care. (2018) 27:S20-4. doi: 10.12968/jowc.2018.27.Sup6.S20

13. Ronci C, Ferraro AS, Lanti A, Missiroli F, Sinopoli S, Del Proposto G, et al. Platelet-rich plasma as treatment for persistent ocular epithelial defects. Transfus Apher Sci. (2015) 52:300-4. doi: 10.1016/j.transci.2014.12.027

14. Alio JL, Rodriguez AE, De Arriba P, Gisbert S, Abdelghany AA. Treatment with platelet-rich plasma of surgically related dormant corneal ulcers. Eur J Ophthalmol. (2018) 28:515-20. doi: 10.1177/1120672117747042

15. Wróbel-Dudzińska D, Alio J, Rodriguez A, Suchodoła-Ratajewicz E, KosiorJarecka E, Rymgayło-Jankowska B, et al. Clinical efficacy of platelet-rich plasma in the treatment of neurotrophic corneal ulcer. J Ophthalmol. (2018) 2018:3538764. doi: 10.1155/2018/3538764

16. Tabrizi R, Karagah T, Shahidi S, Zare N. Does platelet-rich plasma enhance healing in the idiopathic bone cavity? A single-blind randomized clinical trial. Int J Oral Maxillofac Surg. (2015) 44:1175-80. doi: 10.1016/j.ijom.2015.05.011

17. Del Fabbro M, Bucchi C, Lolato A, Corbella S, Testori T, Taschieri S. Healing of Postextraction Sockets Preserved With Autologous Platelet Concentrates. A systematic review and meta-analysis. J Oral Maxillofac Surg. (2017) 75:160115. doi: 10.1016/j.joms.2017.02.009

18. Bhujbal R, Malik NA, Kumar N, Kv S, Parkar MI, Mb J. Comparative evaluation of platelet rich plasma in socket healing and bone regeneration after surgical removal of impacted mandibular third molars. J Dent Res Dent Clin Dent Prospects. (2018) 12:153-8. doi: 10.15171/joddd.2018.024

19. Del Fabbro M, Karanxha L, Panda S, Bucchi C, Nadathur Doraiswamy J, Sankari M, et al. Autologous platelet concentrates for treating periodontal infrabony defects. Cochrane Database Syst Rev. (2018) 11:CD011423. doi: 10.1002/14651858.CD011423.pub2 
20. Saleem M, Pisani F, Zahid FM, Georgakopoulos I, Pustina-Krasniqi T, Xhajanka E, et al. Adjunctive platelet-rich plasma (PRP) in infrabony regenerative treatment: a systematic review and RCT's meta-analysis. Stem Cells Int. (2018) 2018:9594235. doi: 10.1155/2018/9594235

21. Fahie MA, Ortolano GA, Guercio V, Schaffer JA, Johnston G, Au J, et al. randomized controlled trial of the efficacy of autologous platelet therapy for the treatment of osteoarthritis in dogs. J Am Vet Med Assoc. (2013) 243:1291-7. doi: 10.2460/javma.243.9.1291

22. Tambella AM, Attili AR, Dini F, Palumbo Piccionello A, Vullo C, Serri E, et al. Autologous platelet gel to treat chronic decubital ulcers: a randomized, blind controlled clinical trial in dogs. Vet Surg. (2014) 43:726-33. doi: 10.1111/j.1532-950X.2014.12148.x

23. Iacopetti I, Patruno M, Melotti L, Martinello T, Bedin S, Badon $\mathrm{T}$, et al. Autologous platelet-rich plasma enhances the healing of large cutaneous wounds in dogs. Front Vet Sci. (2020) 7:575449. doi: $10.3389 /$ fvets.2020.575449

24. Perego R, Spada E, Baggiani L, Martino PA, Proverbio D. Efficacy of a semi automated commercial closed system for autologous leukocyte- and plateletrich plasma (l-prp) production in dogs: a preliminary study. Animals. (2020) 10:1342. doi: 10.3390/ani10081342

25. Perinelli DR, Bonacucina G, Pucciarelli S, Cespi M, Serri E, Polzonetti V, et al. Rheological properties and growth factors content of Platelet-Rich plasma: relevance in veterinary biomedical treatments. Biomedicines. (2020) 8:429. doi: 10.3390/biomedicines8100429

26. Tambella AM, Bartocetti F, Rossi G, Galosi L, Catone G, Falcone A, et al. Effects of autologous platelet-rich fibrin in post-extraction alveolar sockets: a randomized, controlled split-mouth trial in dogs with spontaneous periodontal disease. Animals. (2020) 10:1343. doi: 10.3390/ani10081343

27. Marx RE. Platelet-rich plasma: evidence to support its use. J Oral Maxillofac Surg. (2004) 62:489-96. doi: 10.1016/j.joms.2003.12.003

28. Bielecki TM, Gazdzik TS, Arendt J, Szczepanski T, Król W, Wielkoszynski T. Antibacterial effect of autologous platelet gel enriched with growth factors and other active substances: an in vitro study. J Bone Jt Surg - Ser B. (2007) 89:417-20. doi: 10.1302/0301-620X.89B3.18491

29. Moojen DJF, Everts PAM, Schure RM, Overdevest EP, Van Zundert A, Knape JTA, et al. Antimicrobial activity of platelet-leukocyte gel against staphylococcus aureus. J Orthop Res. (2008) 26:404-10. doi: 10.1002/jor.20519

30. Drago L, Bortolin M, Vassena C, Taschieri S, Del Fabbro M. Antimicrobial activity of pure platelet-rich plasma against microorganisms isolated from oral cavity. BMC Microbiol. (2013) 13:47. doi: 10.1186/1471-2180-13-47

31. López C, Carmona JU, Giraldo CE, Álvarez ME. Bacteriostatic effect of equine pure platelet-rich plasma and other blood products against methicillinsensitive Staphylococcus aureus: an in vitro study. Vet Comp Orthop Traumatol. (2014) 27:372-8. doi: 10.3415/VCOT-14-04-0054

32. Mariani E, Filardo G, Canella V, Berlingeri A, Bielli A, Cattini L, et al. Plateletrich plasma affects bacterial growth in vitro. Cytotherapy. (2014) 16:1294-304. doi: 10.1016/j.jcyt.2014.06.003

33. Mariani E, Canella V, Berlingeri A, Bielli A, Cattini L, Landini MP, et al. Leukocyte presence does not increase microbicidal activity of Platelet-rich Plasma in vitro clinical microbiology and vaccines. BMC Microbiol. (2015) 15:149. doi: 10.1186/s12866-015-0482-9

34. Yang L-C, Hu S-W, Yan M, Yang J-J, Tsou S-H, Lin Y-Y. Antimicrobial activity of platelet-rich plasma and other plasma preparations against periodontal pathogens. J Periodontol. (2015) 86:310-8. doi: 10.1902/jop.2014.140373

35. Badade PS, Mahale SA, Panjwani AA, Vaidya PD, Warang AD. Antimicrobial effect of platelet-rich plasma and platelet-rich fibrin. Indian J Dent Res. (2016) 27:300-4. doi: 10.4103/0970-9290.186231

36. Aggour RL, Gamil L. Antimicrobial effects of platelet-rich plasma against selected oral and periodontal pathogens. Polish J Microbiol. (2017) 66:31-7. doi: $10.5604 / 17331331.1235227$

37. Karde P, Sethi K, Mahale S, Khedkar S, Patil A, Joshi C. Comparative evaluation of platelet count and antimicrobial efficacy of injectable plateletrich fibrin with other platelet concentrates: an in vitro study. J Indian Soc Periodontol. (2017) 21:97. doi: 10.4103/jisp.jisp_201_17

38. Maghsoudi O, Ranjbar R, Mirjalili SH, Fasihi-Ramandi M. Inhibitory activities of platelet-rich and platelet-poor plasma on the growth of pathogenic bacteria. Iran J Pathol. (2017) 12:79-87. doi: 10.30699/ijp.2017.23386
39. Cieślik-Bielecka A, Bold T, Ziółkowski G, Pierchała M, Królikowska A, Reichert P. Antibacterial activity of leukocyte- and platelet-rich plasma: an in vitro study. Biomed Res Int. (2018) 2018:9471723. doi: 10.1155/2018/9471723

40. Kour P, Pudakalkatti P, Vas A, Das S, Padmanabhan S. Comparative evaluation of antimicrobial efficacy of platelet-rich plasma, platelet-rich fibrin, and injectable platelet-rich fibrin on the standard strains of Porphyromonas gingivalis and Aggregatibacter actinomycetemcomitans. Contemp Clin Dent. (2018) 9:325. doi: 10.4103/ccd.ccd_367_18

41. Çetinkaya RA, Yenilmez E, Petrone P, Yilmaz S, Bektöre B, Simsek B, et al. Platelet-rich plasma as an additional therapeutic option for infected wounds with multi-drug resistant bacteria: in vitro antibacterial activity study. Eur J Trauma Emerg Surg. (2019) 45:555-65. doi: 10.1007/s00068-018-0957-0

42. Anitua E, Alonso R, Girbau C, Aguirre JJ, Muruzabal F, Orive G. Antibacterial effect of plasma rich in growth factors (PRGF®)- Endoret $\AA$ ) against Staphylococcus aureus and Staphylococcus epidermidis strains. Clin Exp Dermatol. (2012) 37:652-7. doi: 10.1111/j.1365-2230.2011.04303.x

43. Pham TAV, Tran TTP, Luong NTM. Antimicrobial effect of platelet-rich plasma against porphyromonas gingivalis. Int J Dent. (2019) 2019:7329103. doi: $10.1155 / 2019 / 7329103$

44. Tohidnezhad M, Varoga D, Wruck CJ, Podschun R, Sachweh BH, Bornemann J, et al. Platelets display potent antimicrobial activity and release human betadefensin 2. Platelets. (2012) 23:217-23. doi: 10.3109/09537104.2011.610908

45. Burnouf T, Chou ML, Wu YW, Su CY, Lee LW. Antimicrobial activity of platelet (PLT)-poor plasma, PLT-rich plasma, PLT gel, and solvent/detergenttreated PLT lysate biomaterials against wound bacteria. Transfusion. (2013) 53:138-46. doi: 10.1111/j.1537-2995.2012.03668.x

46. Rózalski M, Micota B, Sadowska B, Paszkiewicz M, Wieckowska-Szakiel M, Rózalska B. Antimicrobial/anti-biofilm activity of expired blood platelets and their released products. Postepy Hig Med Dosw. (2013) 67:321-5. doi: 10.5604/17322693.1046009

47. Wu X, Ren J, Yuan Y, Luan J, Yao G, Li J. Antimicrobial properties of singledonor-derived, platelet-leukocyte fibrin for fistula occlusion: an in vitro study. Platelets. (2013) 24:632-6. doi: 10.3109/09537104.2012.761685

48. Drago L, Bortolin M, Vassena C, Romanò CL, Taschieri S, Del Fabbro M. Plasma components and platelet activation are essential for the antimicrobial properties of autologous platelet-rich plasma: an in vitro study. PLoS ONE. (2014) 9:e107813. doi: 10.1371/journal.pone.0107813

49. Edelblute CM, Donate AL, Hargrave BY, Heller LC. Human platelet gel supernatant inactivates opportunistic wound pathogens on skin. Platelets. (2015) 26:13-6. doi: 10.3109/09537104.2013.863859

50. Intravia J, Allen DA, Durant TJS, McCarthy MBR, Russell R, Beitzel K, et al. In vitro evaluation of the anti-bacterial effect of two preparations of platelet rich plasma compared with Cefazolin and whole blood. Muscles Ligaments Tendons J. (2014) 4:79-84. doi: 10.11138/mltj/2014.4.1.079

51. Aktan Í, Dunkel B, Cunningham FM. Equine platelets inhibit E coli growth and can be activated by bacterial lipopolysaccharide and lipoteichoic acid although superoxide anion production does not occur and platelet activation is not associated with enhanced production by neutrophils. Vet Immunol Immunopathol. (2013) 152:209-17. doi: 10.1016/j.vetimm.2012.12.007

52. Gilbertie JM, Schaer TP, Schubert AG, Jacob ME, Menegatti S, Ashton Lavoie $\mathrm{R}$, et al. Platelet-rich plasma lysate displays antibiofilm properties and restores antimicrobial activity against synovial fluid biofilms in vitro. J Orthop Res. (2020) 38:1365-74. doi: 10.1002/jor.24584

53. $\mathrm{Li} \mathrm{H}, \mathrm{Li}$ B. PRP as a new approach to prevent infection: preparation and in vitro antimicrobial properties of PRP. J Vis Exp. (2013) 74:e50351. doi: $10.3791 / 50351$

54. Del Fabbro M, Bortolin M, Taschieri S, Ceci C, Weinstein RL. Antimicrobial properties of platelet-rich preparations. A systematic review of the current pre-clinical evidence. Platelets. (2016) 27:276-85. doi: 10.3109/09537104.2015.1116686

55. D'asta F, Halstead F, Harrison P, Zecchi Orlandini S, Moiemen N, Lord J. The contribution of leucocytes to the antimicrobial activity of plateletrich plasma preparations: a systematic review. Platelets. (2018) 29:9-20. doi: 10.1080/09537104.2017.1317731

56. Varshney S, Dwivedi A, Pandey V. Antimicrobial effects of various platelet rich concentrates-vibes from in-vitro studies-a systematic review. J Oral Biol Craniofacial Res. (2019) 9:299-305. doi: 10.1016/j.jobcr.2019.06.013 
57. Cetinkaya RA, Yilmaz S, Ünlü A, Petrone P, Marini C, Karabulut E, et al. The efficacy of platelet-rich plasma gel in MRSA-related surgical wound infection treatment: an experimental study in an animal model. Eur J Trauma Emerg Surg. (2018) 44:859-67. doi: 10.1007/s00068-017-0852-0

58. Serraino GF, Dominijanni A, Jiritano F, Rossi M, Cuda A, Caroleo S, et al. Platelet-rich plasma inside the sternotomy wound reduces the incidence of sternal wound infections. Int Wound J. (2013) 12:260-4. doi: 10.1111/iwj.12087

59. Hamman BL, Stout LY, Theologes TT, Sass DM, Da Graca B, Filardo G. Relation between topical application of platelet-rich plasma and vancomycin and severe deep sternal wound infections after a first median sternotomy. Am J Cardiol. (2014) 113:1415-9. doi: 10.1016/j.amjcard.2013.12.046

60. Yuan T, Zhang C, Zeng B. Treatment of chronic femoral osteomyelitis with platelet-rich plasma (PRP): a case report. Transfus Apher Sci. (2008) 38:16773. doi: 10.1016/j.transci.2008.01.006

61. Jia WT, Zhang CQ, Wang JQ, Feng Y, Ai ZS. The prophylactic effects of platelet-leucocyte gel in osteomyelitis: an experimental study in a rabbit model. J Bone Jt Surg - Ser B. (2010) 92:304-10. doi: 10.1302/0301-620X.92B2.22042

62. Li GY, Yin JM, Ding H, Jia WT, Zhang CQ. Efficacy of leukocyte- and plateletrich plasma gel (L-PRP gel) in treating osteomyelitis in a rabbit model. $J$ Orthop Res. (2013) 31:949-56. doi: 10.1002/jor.22299

63. Li H, Hamza T, Tidwell JE, Clovis $\mathrm{N}$, Li B. Unique antimicrobial effects of platelet-rich plasma and its efficacy as a prophylaxis to prevent implant-associated spinal infection. Adv Healthc Mater. (2013) 2:1277-84. doi: 10.1002/adhm.201200465

64. Mirzaei M, Daneshpajooh A, Farsinezhad A, Jafarian Z, Ebadzadeh MR, Saberi $\mathrm{N}$, et al. The therapeutic effect of intravesical instillation of platelet rich plasma on recurrent bacterial cystitis in women: a randomized clinical trial. Urol J. (2019) 16:609-13. doi: 10.22037/uj.v0i0.5239

65. Sangiovanni TP, Kiebzak GM. Prospective randomized evaluation of intraoperative application of autologous platelet-rich plasma on surgical site infection or delayed wound healing. Foot Ankle Int. (2016) 37:470-7. doi: 10.1177/1071100715623994

66. Farghali HA, AbdElKader NA, AbuBakr HO, Aljuaydi SH, Khattab MS, Elhelw R, et al. Antimicrobial action of autologous platelet-rich plasma on MRSA-infected skin wounds in dogs. Sci Rep. (2019) 9:12722. doi: 10.1038/s41598-019-48657-5

67. Tarantino F, Flores A, Gobbi A, Salomé D. Un nuovo semplice metodo per l'ottenimento della colla di fibrina autologa ad uso chirurgico. La Trasfus del sangue. (2001) 46:37-46.

68. Soffer E, Ouhayoun JP, Dosquet C, Meunier A, Anagnostou F. Effects of platelet lysates on select bone cell functions. Clin Oral Implants Res. (2004) 15:581-8. doi: 10.1111/j.1600-0501.2004.01063.x

69. Eberl C, Speth C, Jacobsen ID, Hermann M, Hagleitner M, Deshmukh H, et al. Candida: Platelet interaction and platelet activity in vitro. J Innate Immun. (2018) 11:52-62. doi: 10.1159/000491030

70. Magiorakos AP, Srinivasan A, Carey RB, Carmeli Y, Falagas ME, Giske $\mathrm{CG}$, et al. Multidrug-resistant, extensively drug-resistant and pandrugresistant bacteria: An international expert proposal for interim standard definitions for acquired resistance. Clin Microbiol Infect. (2012) 18:268-81. doi: 10.1111/j.1469-0691.2011.03570.x

71. Clinical and Laboratory Standards Institute (CLSI). Performance Standards for Antimicrobial Disk and Dilution Susceptibility Tests for Bacteria Isolated From Animals. In: 4th ed., ed. CLSI supplement VET08. Wayne, PA: Clinical and Laboratory Standards Institute (2018).

72. The European Committee on Antimicrobial Susceptibility Testing (EUCAST). Breakpoint tables for interpretation of MICs and zone diameters. (2018) Version 8.1. Available online at: http://www.eucast.org/

73. Leitner GC, Gruber R, Neumüller J, Wagner A, Kloimstein P, Höcker P, et al. Platelet content and growth factor release in platelet-rich plasma: a comparison of four different systems. Vox Sang. (2006) 91:135-9. doi: 10.1111/j.1423-0410.2006.00815.x

74. Rughetti A, Gallo R, Caloprisco G, Borean A, Necozione S, Dell'Orso L, et al. Platelet gel: assays of three growth factors. Blood Transfus. (2006) 4:92-101.

75. McCarrel T, Fortier L. Temporal growth factor release from platelet-rich plasma, trehalose lyophilized platelets, and bone marrow aspirate and their effect on tendon and ligament gene expression. J Orthop Res. (2009) 27:103342. doi: 10.1002/jor.20853
76. Giusti I, Rughetti A, D’Ascenzo S, Millimaggi D, Pavan A. Dell'Orso L, Dolo $\mathrm{V}$. Identification of an optimal concentration of platelet gel for promoting angiogenesis in human endothelial cells. Transfusion. (2009) 49:771-8. doi: 10.1111/j.1537-2995.2008.02033.x

77. Tambella AM, Attili AR, Dupré G, Cantalamessa A, Martin S, Cuteri V, et al. Platelet-rich plasma to treat experimentally-induced skin wounds in animals: a systematic review and meta-analysis. PLoS ONE. (2018) 13:e0191093. doi: 10.1371/journal.pone.0191093

78. Mazzucco L, Balbo V, Guaschino R. "Reasonable compromise" to define the quality standards of platelet concentrate for non-transfusion use (CPunT). Transfus Apher Sci. (2012) 47:207-11. doi: 10.1016/j.transci.2012.06.006

79. Perego R, Proverbio D, Baggiani L, Nora Roggero BDGG SE. In house double centrifugation method for preparation of homologous platelet-rich plasma (Prp) in dogs EC. Vet Sci. (2016) 2:126-32.

80. Bielecki TM, Dohan Ehrenfest D, A Everts P, Wiczkowski A. The role of leukocytes from L-PRP/L-PRF in wound healing and immune defense: new perspectives. Curr Pharm Biotechnol. (2012) 13:1153-62. doi: $10.2174 / 138920112800624373$

81. Cieślik-Bielecka A, Reichert P, Skowroński R, Królikowska A, Bielecki T. A new aspect of in vitro antimicrobial leukocyte- and platelet-rich plasma activity based on flow cytometry assessment. Platelets. (2019) 30:728-36. doi: 10.1080/09537104.2018.1513472

82. Prysak MH, Lutz CG, Zukofsky TA, Katz JM, Everts PA, Lutz GE. Optimizing the safety of intradiscal platelet-rich plasma: an in vitro study with Cutibacterium acnes. Regen Med. (2019) 14:955-67. doi: 10.2217/rme-2019-0098

83. Giusti I, Di Francesco M, D’Ascenzo S, Palumbo P, Rughetti A, Dell'Orso $\mathrm{L}$, et al. Leukocyte depletion does not affect the in vitro healing ability of platelet rich plasma. Exp Ther Med. (2018) 15:4029-38. doi: 10.3892/etm.20 18.5887

84. Yeaman MR. The role of platelets in antimicrobial host defense. Clin Infect Dis. (1997) 25:951-68. doi: 10.1086/516120

85. Klinger MHF, Jelkmann W. Role of blood platelets in infection and inflammation. J Interf Cytokine Res. (2002) 22:913-22. doi: 10.1089/10799900260286623

86. Bayer A, Lammel J, Rademacher F, Groß J, Siggelkow M, Lippross S, et al. Platelet-released growth factors induce the antimicrobial peptide human beta-defensin-2 in primary keratinocytes. Exp Dermatol. (2016) 25:460-5. doi: 10.1111/exd.12966

87. Tang YQ, Yeaman MR, Selsted ME. Antimicrobial peptides from human platelets. Infect Immun. (2002) 70:6524-33. doi: 10.1128/IAI.70.12.6524-6533.2002

88. Mussano F, Genova T, Munaron L, Petrillo S, Erovigni F, Carossa S. Cytokine, chemokine, and growth factor profile of platelet-rich plasma. Platelets. (2016) 27:467-71. doi: 10.3109/09537104.2016.1143922

89. Zhang W, Guo Y, Kuss M, Shi W, Aldrich AL, Untrauer J, et al. Platelet-rich plasma for the treatment of tissue infection: Preparation and clinical evaluation. Tissue Eng - Part B Rev. (2019) 25:225-36. doi: $10.1089 /$ ten.teb.2018.0309

Conflict of Interest: The authors declare that the research was conducted in the absence of any commercial or financial relationships that could be construed as a potential conflict of interest.

Publisher's Note: All claims expressed in this article are solely those of the authors and do not necessarily represent those of their affiliated organizations, or those of the publisher, the editors and the reviewers. Any product that may be evaluated in this article, or claim that may be made by its manufacturer, is not guaranteed or endorsed by the publisher.

Copyright (C) 2021 Attili, Iacoucci, Serri, Cuteri, Cantalamessa, Linardi, Rifici, Mazzullo, Rossi, Galosi and Tambella. This is an open-access article distributed under the terms of the Creative Commons Attribution License (CC BY). The use, distribution or reproduction in other forums is permitted, provided the original author(s) and the copyright owner(s) are credited and that the original publication in this journal is cited, in accordance with accepted academic practice. No use, distribution or reproduction is permitted which does not comply with these terms. 